\title{
EVALUACIÓN INTEGRAL DE "PUENTE DE PIEDRA", GRECIA, COSTA RICA Y SU POTENCIAL TURÍSTICO
}

\author{
INTEGRAL CONDITION ASSESSMENT OF “PUENTE DE PIEDRA", GRECIA, \\ COSTA RICA AND ITS TOURISM POTENTIAL
}

\author{
Paulo Ruiz y Carolina Suárez* \\ Laboratorio Nacional de Materiales y Modelos Estructurales (LANAMME- \\ UCR), Universidad de Costa Rica \\ *Autor para contacto: paulo.ruizcubillo@ucr.ac.cr
}

(Recibido: 24/03/2017; aceptado: 07/06/2017)

\begin{abstract}
Puente de Piedra is a structure located in the southwest flank of the Poás volcano, originated from differential erosion processes active for thousands of years in volcanic rocks (ignimbrite deposits) by the Poró river. It was declared a natural heritage of Costa Rica on April 21, 1994, under the decree number 23 1111- 06 and because of its nature as relatively young age (Middle Pleistocene), size and functionality is one of the few worldwide. For these reasons, its preservation is very important to be enjoyed by future generations. A geological and geomorphological characterization of the bridge is presented, also the region in which it is located, along with an assessment of their current status and inventory of damages, human activities that take place in the region are also identified and how the changes in them could negatively impact it in the future. To have the detailed geomorphological description of the bridge, we used a lidar survey and a 3D model to obtain all the parametric data that also can be use as historical memory of the structure. The results of this work can be the starting point for defining an intervention program, conservation and maintenance of the structure, also an incentive for the community of Grecia that can have greater tourist use of this site. Currently the tourism is detached and with no interconnections in terms of geological, biological and cultural aspects. Linking these fields could help to improve the development of communities near the volcano and take the first steps towards a concept of geopark.
\end{abstract}

Keywords: natural bridge, differential erosion, lidar, evaluation, slopes, traffic, geopark.

Resumen: El Puente de Piedra es una estructura ubicada en el flanco suroeste del volcán Poás, fue formada por procesos de erosión diferencial en rocas volcánicas (depósitos ignimbríticos) que han estado activos por miles de años, en el río Poró. Su importancia radica en que fue declarado patrimonio natural de Costa Rica el 21 de abril de 1994, bajo el decreto número 23 1111- 06, y que por sus características como: edad (Pleistoceno Medio) tamaño y funcionalidad, es uno de los pocos que hay en el mundo. Por estas razones es que su preservación es muy importante para asegurar el disfrute por las próximas generaciones. Se presenta una caracterización geológica y geomorfológica no solo el puente, si no la región en la que está ubicado, además de la evaluación de su estado actual con un inventario de daños

Ruiz, P. y Suárez, C. (2017). Evaluación integral de "Puente de Piedra", Grecia, Costa Rica y su potencial turístico. Revista Geológica de América Central, 57, 121-147. doi: 10.15517/rgac.v0i57.30151 
y problemas que lo afectan. Se identifica el uso de la tierra en su entorno y como el cambio en ellas lo impactaría negativamente en el futuro. Para realizar la descripción geomorfológica detallada del puente se realizó un levantamiento lídar de la estructura y se generó un modelo 3D de la estructura, del cual se obtuvieron sus datos paramétricos y que también se utilizará como memoria histórica de la estructura. Los resultados obtenidos de este trabajo pueden ser el punto de partida para definir un programa de intervención, conservación y mantenimiento de la estructura, así como un incentivo para que la comunidad de Grecia pueda generar y disfrutar de un mayor aprovechamiento turístico de este sitio. Actualmente la oferta turística de sitios con atractivo geológico alrededor del volcán Poás funcionan de forma desligada y no hay interconexiones en cuanto a los aspectos geológicos, biológicos y culturales. Ligando estos campos se podría ayudar a fomentar el desarrollo de las comunidades cercanas al volcán y se podrían dar los primeros pasos hacia un concepto de geoparque.

Palabras clave: puente natural, erosión diferencial, lídar, evaluación, pendientes, tránsito, geoparque.

\section{INTRODUCCIÓN}

La conservación y el mantenimiento de las obras civiles construidas para comunicar dos regiones separadas por pasos fluviales, junto con la caracterización de sus materiales y el inventario de problemas que lo afectan, son el punto de partida para definir un programa de intervención vital para alargar su vida útil.

A lo largo de la historia, para la construcción de puentes se han utilizado distintos materiales y tipos de estructuras. Los puentes de mampostería de piedra fueron desarrollados desde la época de los romanos en el siglo I a.C y dominaron gran parte de la historia constructiva, con la técnica de la bóveda con dovelas. Su dominio se mantuvo sin cambios importantes hasta el siglo XVIII donde los primeros ingenieros franceses innovaron en la proyección y construcción de los puentes de piedra (Bardales, 2013).

Actualmente ya no se construyen puentes de mampostería de piedra, porque resultan excesivamente costosos, salvo casos excepcionales, como en parques o lugares naturales protegidos con una intención puramente paisajística, y muchos de ellos son de concreto enchapados con piedra.

Además de los puentes de mampostería de piedra construidos por el ser humano, existen también puentes de piedra de origen natural. Estos son más escasos y han sido formados por procesos de meteorización y erosión naturales que han interactuado con la roca durante mucho tiempo hasta que la llega a atravesar y crear una abertura en la parte inferior del macizo, permitiendo el paso fluvial, es entonces cuando el macizo rocoso actúa como puente o arco natural.

Estas estructuras naturales dependen de sus características geológicas y geotécnicas, para que funcionen como puente y permitan el paso de personas y hasta de vehículos. En su mayoría, debido a factores como: ubicación, dimensiones, altura y estabilidad del macizo rocoso, no son aptos para el paso de vehículos en su parte superior, por lo que se aprovecha la abertura en la parte inferior como un túnel, y así pueden servir como pasadizos turísticos o se utilizan para el paso de carreteras que no afecten el macizo. Estas estructuras, acompañan el paisaje y suelen ser un atractivo turístico aprovechado principalmente por las comunidades locales. Más adelante se mencionan detalles sobre este tipo de puentes en varias partes del mundo que tienen esta función además se resumen en el cuadro 1.

En algunos países, este tipo de estructuras han sido declaradas patrimonio natural y su preservación va más allá de la utilidad que se le da al puente o arco, ya que se busca que muchas generaciones puedan disfrutar de su belleza, y por esta razón, la preservación se considera aún más importante.

Uno de estos casos es el Puente de Piedra, que se ubica en el cantón de Grecia y fue declarado patrimonio natural de Costa Rica por el decreto $\mathrm{N}^{\circ} 23$ 1111-06 del 21 de abril de 1994. Pese a esta declaratoria, el mantenimiento y programas de conservación de esta estructura natural han 
Cuadro 1

Comparación entre puentes naturales citados en este documento que tienen o han tenido algún tipo de función en su parte superior.

\begin{tabular}{|c|c|c|c|c|}
\hline Nombre/Ubicación & $\begin{array}{l}\text { Puente de Piedra } \\
\text { (Costa Rica) }\end{array}$ & $\begin{array}{l}\text { Puentedey } \\
\text { (España) }\end{array}$ & $\begin{array}{l}\text { Puente Inca } \\
\text { (Argentina) }\end{array}$ & $\begin{array}{c}\text { Puente Creek } \\
\text { (Estados Unidos) }\end{array}$ \\
\hline Material & $\begin{array}{l}\text { Roca volcánica, Ignim- } \\
\text { britas }\end{array}$ & Roca caliza & Rocas clásticas & Roca caliza \\
\hline Dimensiones & $\begin{array}{c}36 \mathrm{~m} \text { largo, } 7 \mathrm{~m} \text { ancho, } \\
11,5 \mathrm{~m} \text { espesor }\end{array}$ & $\begin{array}{l}75 \mathrm{~m} \text { largo, } 34 \mathrm{~m} \\
\text { ancho, } 15 \mathrm{~m} \text { alto }\end{array}$ & $\begin{array}{l}47 \mathrm{~m} \text { largo, } 28 \mathrm{~m} \\
\text { ancho, } 8 \mathrm{~m} \text { espesor }\end{array}$ & $\begin{array}{c}\text { 12,2 m de largo, 6,1 } \\
\text { m de ancho, } 1 \mathrm{~m} \text { mín. } \\
\text { espesor }\end{array}$ \\
\hline $\begin{array}{c}\text { Edad de las rocas que } \\
\text { lo forman }\end{array}$ & Pleistoceno Medio & Cretácico Superior & Mioceno & Pleistoceno \\
\hline Uso actual & $\begin{array}{c}\text { Paso vehicular, Ruta } \\
\text { Cantonal }\end{array}$ & $\begin{array}{l}\text { Casas de habitación } \\
\text { encima del puente }\end{array}$ & Paso peatonal turístico & $\begin{array}{c}\text { Actividades recreativas } \\
\text { turísticas }\end{array}$ \\
\hline
\end{tabular}

sido mínimos. Además de estos inconvenientes, se considera que a esta estructura natural no se le está dando la importancia que se merece y se estaría desperdiciando su gran potencial turístico. Es por estas razones, que en este trabajo se busca caracterizar geológicamente no solo el puente, si no la región en la que está ubicado, además determinar su estado actual con un inventario de daños y problemas e identificar las actividades humanas que se realizan en su entorno y cómo algún cambio en ellas podría impactar negativamente el puente. Finalmente se propone la posibilidad de incluir al Puente de Piedra dentro de una ruta turística por los principales atractivos geológicos y naturales del volcán Poás, fomentando así el desarrollo sostenible de la comunidad de la zona y aprovechamiento turístico de esta estructura.

\section{PUENTES DE PIEDRA NATURALES EN EL MUNDO}

Existen ejemplos de otros puentes naturales en el mundo que son transitados y utilizados como vía de comunicación en la parte superior y no como túneles (Cuadro 1). Uno de ellos es el puente de Puentedey (Puente de Dios) formado en roca caliza de edad Cretácico Superior, atravesado por el río Nela en su paso por el poblado de Puentedey en la provincia de Burgos, España. El arco tiene su origen en una cavidad kárstica que persiste como relicto de un antiguo sistema de oquedades subterráneas que la erosión ha dejado al descubierto (Porres, 2007). El volumen de la cavidad se ha incrementado desde que el río Nela abandonó su meandro original y actualmente tiene dimensiones de $15 \mathrm{~m}$ de alto, $34 \mathrm{~m}$ de ancho y $75 \mathrm{~m}$ de largo. El arco natural está integrado en el poblado de Puentedey, constituido por casas montañesas. Tiene una fragilidad baja por lo que como medida de protección se mantiene un paraje natural. Este puente es visitado por miles de personas cada año y la comunidad de Puentedey se beneficia directamente esta actividad.

Otro ejemplo, pero en América del Sur es el Puente Inca de las Cuevas en Mendoza, Argentina. Su formación tiene dos teorías principales, una es que el recorrido del agua socavó un depósito fluvio-glacial, y la otra es que se formó primariamente un puente de hielo durante la época postglacial y después diferentes avalanchas aportaron material clástico a la formación, por lo que se le caracteriza como una secuencia volcánica, ya que muestra filones de andesita (Ramos et al. 1996). Su cementación se debe al constante flujo y contacto con las aguas termales ricas en carbonatos y sulfato de calcio. Tiene una edad estimada del periodo Mioceno (Ramos et al. 1996).

En la preservación de este puente natural en Argentina, tuvieron que tomar en cuenta componentes minerales y biológicos, como las aguas termales de elevada salinidad y colonias de algas macro y microscópicas. Este puente natural tiene forma elíptica y sus dimensiones son $47 \mathrm{~m}$ de largo, $28 \mathrm{~m}$ de ancho y $8 \mathrm{~m}$ de espesor y la altura a nivel del agua llega a $27 \mathrm{~m}$, sobre el río 
Las Cuevas, pendiendo de ella hay estalactitas de color amarillo por el aporte de azufre de la formación (Rodríguez, 2005). Este sitio está incluido dentro de la atracciones turísticas que comúnmente se visitan en este sector de la cordillera de los Andes, los paquetes turísticos que lo incluyen no solo se venden del lado argentino, sino también del lado chileno ya que se encuentra a solo $15 \mathrm{~km}$ de la frontera entre estos dos países y junto a la Ruta No. 7 que lleva desde la frontera a la ciudad de Mendoza.

Como último ejemplo se encuentra el Puente Creek en el sur de la Florida en Estados Unidos. Está compuesto por piedra caliza de edad Pleistoceno, donde el agua, en vez de atravesar, cortó la parte de inferior de la unidad, formando un arco de piedra. Otras teorías explican su origen a una caverna parcialmente colapsada por gravedad. También se explica que por acción de agua subterránea ácida, de forma gradual debilitó el techo el túnel y eventualmente se abrió el agüero de mayor tamaño en la caliza, con dimensiones de 12,2 $\mathrm{m}$ de longitud, 6,1 $\mathrm{m}$ de ancho y hasta 1,6 m de espesor (Perry, 1982).

El puente tuvo ocupación por los indígenas Tequeste y los pioneros del siglo XIX, existieron asentamientos alrededor de la zona del puente y fue un importante punto local para las actividades humanas. Actualmente es conservado y considerado un sitio arqueológico y turístico de importancia nacional donde se desarrollan actividades recreativas; en 1985 fue designado en el Registro de Sitios Históricos Nacionales (Perry, 1982).

\section{Ubicación del Puente de Piedra}

El puente natural se ubica en el flanco suroeste del volcán Poás (hoja topográfica Puente de Piedra, escala 1:10 000 del Instituto Geográfico Nacional, IGN), en la vertiente pacífica, donde se registran precipitaciones anuales promedio de entre 3000-4000 mm (PNUD-IMN-MINAET 2009). La estructura analizada, se ubica en el distrito también llamado Puente de Piedra, en el cantón de Grecia, provincia de Alajuela, específicamente en la coordenadas es 464174 N/ 1110400 E, según la proyección CRTM-2005 (Figura 1).

La estructura del Puente de Piedra es de origen volcánico y se encuentra dentro del edificio del estratovolcán complejo Poás, de edad < $1 \mathrm{Ma}$ (Ruiz et al., 2010, Alvarado y Gans 2012). Comparativamente a nivel mundial con otros arcos naturales que tienen funcionabilidad en su parte superior (Cuadro 1), la edad de sus materiales es relativamente joven y es de tamaño pequeño. El hecho de que esta estructura se encuentra ubicada en una zona tropical de alta pluviosidad, probablemente ha influido para que se forme más rápido que otras estructuras en otras latitudes con menor cantidad de precipitaciones. $\mathrm{Su}$ uso como paso vehicular y la vegetación limita su apreciación y podría estar acelerando su desgaste, además de que no se aprovecha todo su potencial turístico.

El objetivo principal de este trabajo es realizar una caracterización geológica e integral de la región y específicamente del estado actual del Puente de Piedra, para que posteriormente se pueda definir un programa de intervención, conservación y mantenimiento de la estructura y así colaborar en la preservación del patrimonio natural del cantón de Grecia. Al mismo tiempo, se busca generar información que pueda ser utilizada por la comunidad como un insumo para aprovechar el potencial turístico del lugar.

\section{METODOLOGÍA}

Se realizó trabajo de campo en el sector de Grecia, en las cercanías del puente y específicamente en el sitio del Puente de Piedra. En esta zona, se realizó una revisión y obtención de datos geológicos, geomorfológicos, geotécnicos y de uso de la tierra para generar mapas temáticos con los aspectos evaluados. Estos mapas se presentan sobre modelos de elevación digital (MED) con curvas de nivel cada $5 \mathrm{~m}$ a partir de información del Instituto Geográfico Nacional (IGN). 


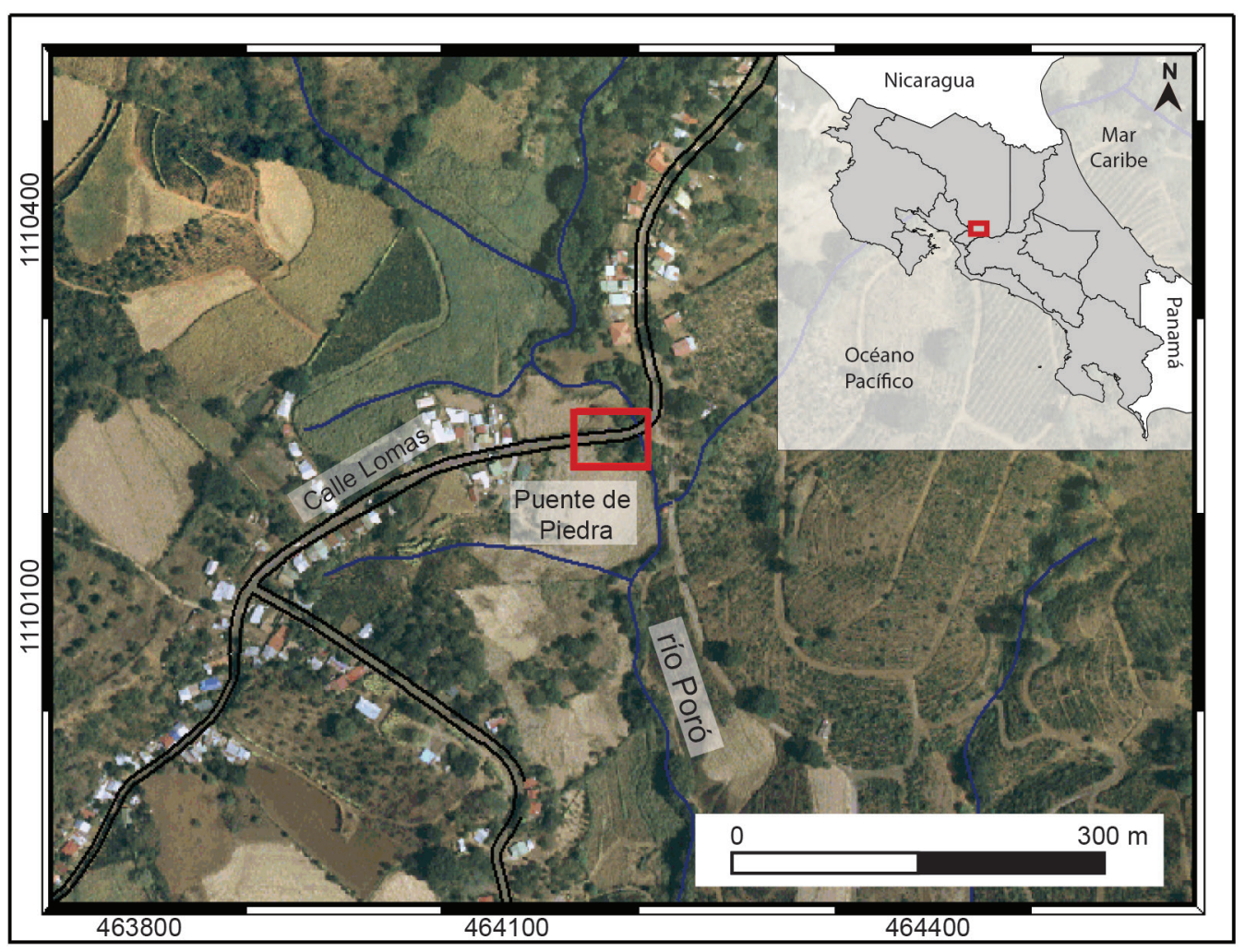

Fig. 1: Ubicación de Puente de Piedra. La fotografía aérea de la zona de estudio fue obtenida de basemaprcgis 10.2, en ella se puede observar que el uso actual de la tierra corresponde principalmente con cultivos, y uso residencial.

Mediante un escáner lídar terrestre se realizó un levantamiento digital de la estructura del Puente de Piedra con una resolución de nivel medio, es decir, se trabajó a una distancia de $50 \mathrm{~m}$ y la separación de los puntos del modelo obtenido se reduce a $2 \mathrm{~cm}$ (Ruiz et al., 2014), para tener una memoria digital del sitio y generar un modelo de tres dimensiones (3D) de la estructura. Los modelos de puntos están disponibles a quien los solicite en el Laboratorio Nacional de Materiales y Modelos Estructurales de la Universidad de Costa Rica (LanammeUCR). Con este modelo 3D se determinaron los datos paramétricos de la estructura y se identificaron los principales daños. Finalmente se incluyeron los datos de un estudio de tránsito promedio diario realizado en octubre del 2014 sobre el puente y se analizó cómo el tránsito de la zona podría variar, si cambian el tipo de actividades que se realizan actualmente y cuáles podrían ser las implicaciones en el Puente de Piedra.

\section{Caracterización geomorfológica}

El área total de la zona que fue caracterizada en este trabajo es de aproximadamente $20 \mathrm{~km}^{2}$, los límites de altitud presentes van desde los 1015 m s.n.m. en el sector noreste hasta 712 m s.n.m. en el sector suroeste. La estructura del Puente de Piedra se ubica a una altitud de $812 \mathrm{~m}$ s.n.m. en el sector sur de la zona de estudio (Fig. 2A).

La unidad geomorfológica que predomina es de origen denudacional volcánico, específicamente laderas con materiales volcánicos (lavas y 
piroclastos principalmente) con pendiente entre moderada $\left(16^{\circ}-35^{\circ}\right)$ y baja $\left(<10^{\circ}\right)$. Las zonas más planas con pendiente entre $0^{\circ}$ a $4^{\circ}$ se encuentran en las cúspides de las laderas y están compuestas en su mayoría por material clástico y coladas de lava cubiertas por cenizas, que conforman una espesa capa de suelo regolito en algunos casos de varios metros de espesor. Las laderas de pendiente moderada se encuentran disectadas por ríos y quebradas que constituyen el sistema de drenaje de la zona. Este sistema de ríos y quebradas, ha erosionando poco a poco los materiales de las laderas hasta llegar a generar valles fluviales alargados y laderas con pendientes entre $16^{\circ}-35^{\circ}$.

Con respecto a las estructuras, al noroeste del Puente de Piedra se ubica parte del escarpe de la falla de Alajuela. Esta falla de tipo inversa, tiene una extensión de aproximadamente $4 \mathrm{~km}$ dentro de la zona de estudio, pero que se extiende un total de $20 \mathrm{~km}$ desde la ciudad de Grecia al oeste, con rumbo variable entre E-W y WNW (Denyer et al., 2003, Montero et al., 2010). Otras estructuras menores se presentan con expresiones geomorfológicas como alineamientos con rumbo $\mathrm{N}-\mathrm{S}$, usualmente en valles fluviales, y una de ellas en el río Poró que atraviesa el sitio donde se ubica el Puente de Piedra (Fig. 2A).

En general, el sistema de drenaje se caracteriza por una transición entre pie de monte y zonas más planas, donde las nacientes de los ríos de la zona se ubican fuera del área, a casi 2500 m s.n.m. en el sector de la SW de la cima del volcán Poás. El sistema de drenaje en los alrededores del Puente de Piedra es de tipo dendrítico con ríos que en general presentan un comportamiento levemente meándrico determinado por cambios abruptos de dirección en poca distancia. Según la clasificación de zonas del sistema fluvial idealizado por Schumm (1997), el Puente de Piedra, se ubica en una zona de transición, de un área de producción de escorrentía y sedimentos debido a su altitud (812 m s.n.m.) y variedad de pendientes, donde el clima, el diastrofismo y el uso de la tierra causan un efecto significativo en los drenajes, a un área con drenajes más o menos lineales sin mucho aporte de escorrentías por partes altas y que da inicio al sistema meándrico antes de llegar a la zona de sedimentación.
De acuerdo con la cantidad de ríos por kilómetro cuadrado, la densidad de drenaje de la zona es baja o de textura gruesa, donde hay un total de $62 \mathrm{~km}$ de longitud de ríos en un área de 21 $\mathrm{km}^{2}$, por lo que presenta una densidad de drenaje de $2,9 \mathrm{~km} / \mathrm{km}^{2}$, que corresponden con laderas suavizadas, de baja a media precipitación y substratos permeables utilizando la clasificación de Gutiérrez (2008).

Según el sistema de canal fluvial, el río Poró que dio origen al Puente de Piedra, tiene una curva fluvial meandriforme con un carácter de sinuosidad donde el cauce es más ancho en las curvas y con umbrales frecuentes, y es caracterizado además por su baja profundidad de menos de $2 \mathrm{~m}$, según la clasificación de Gutiérrez (2008).

En los alrededores (200 m aguas arriba y aguas abajo) del Puente de Piedra, los márgenes del río presentan pendientes altas $>35^{\circ}$, y la estructura del puente contiene paredes casi verticales a ambos lados.

Puente de Piedra es una estructura que se caracteriza por ser relativamente plana en la parte superior, con un pequeño montículo en el margen norte. Presenta una forma curva cóncava hacia el sector de aguas arriba del río Poró. En la parte superior, tiene dimensiones de $7 \mathrm{~m}$ de ancho y 36 $\mathrm{m}$ de largo (Fig. 3A).

En la parte inferior central se ubica la forma de arco que deja pasar el agua. Se trata de una abertura semicircular con el dintel arqueado, con un ancho y altura máximo en la sección de entrada de 12,3 m y 6,3 m, y mínimo en la sección intermedia de $8,1 \mathrm{~m}$ y 4,6 m (Fig. 3B). Tiene una abertura pequeña al pie del macizo en la pared izquierda, generado por la escorrentía y el mal manejo de aguas superficiales en esta margen del río (Fig. 3C).

\section{Caracterización geológica}

Geográficamente, Puente de Piedra se ubica dentro del macizo del volcán Poás, sin embargo los productos volcánicos que se encuentran en la zona podrían estar también relacionados con el volcán Barva. Es así como la geología regional, se enmarca con productos de estos dos macizos: 


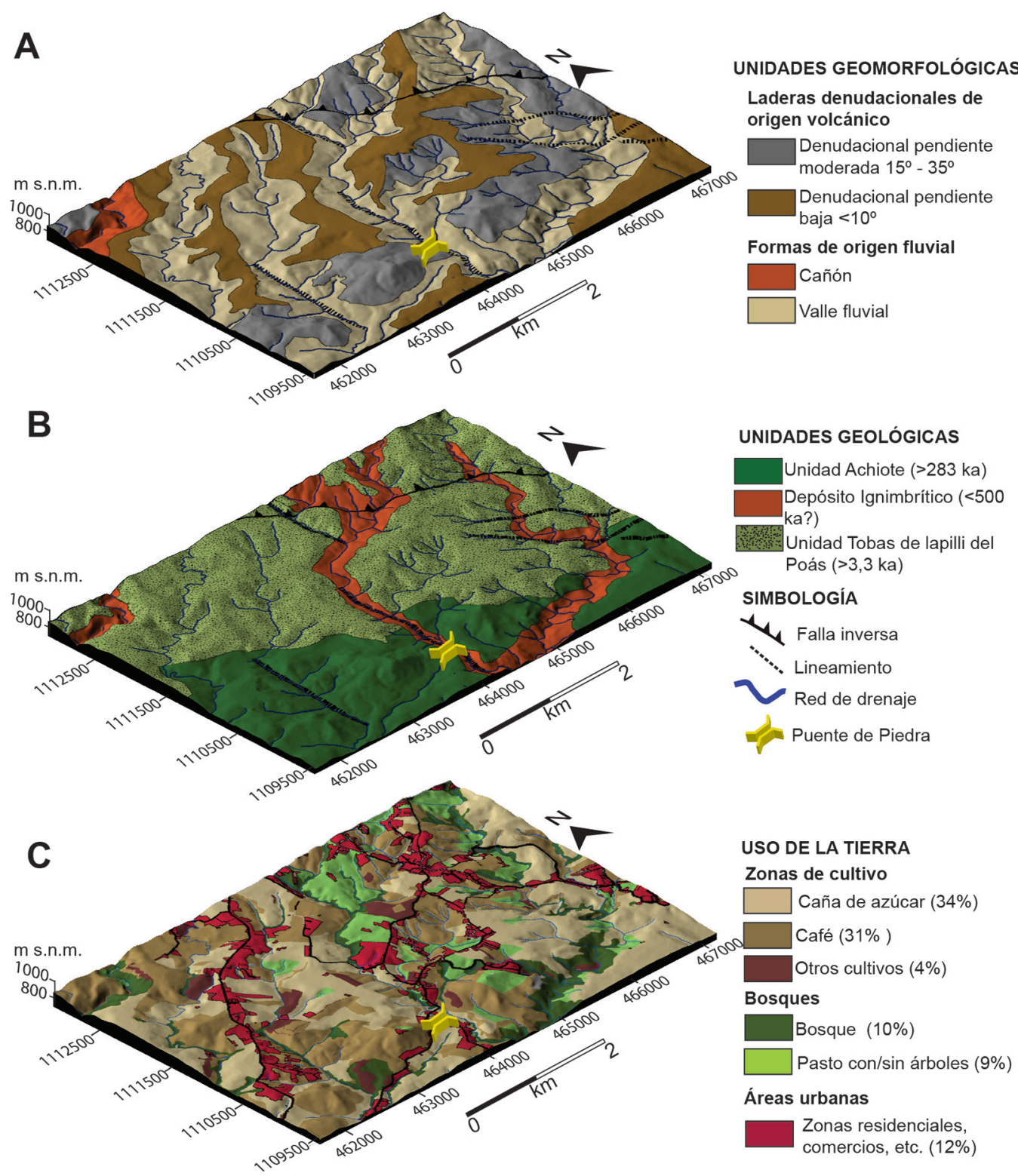

Fig. 2: A) Mapa geomorfológico, se definen 4 unidades para este trabajo. B) Mapa geológico basado en (Ruiz et al., 2010 y Huapaya y Rojas, 2012). C) Mapa de uso del tierra, con sus porcentajes según su uso, relativos al área de estudio, generado para este trabajo a partir de fotografías aéreas del PRUGRAM (2010) y Google Earth.

flujos ignimbríticos, coladas de lava, material de caída y lahares, entre otros (Fig. 2B). El basamento geológico de la zona lo conforman depósitos de tobas e ignimbritas, que podrían estar asociados con el Miembro Puente Mulas de la Formación Colima, o con la ignimbrita de la Formación Tiribí (atribuida al volcán Barva) y que habían sido expuestos por la erosión fluvial. El sector sur del área de estudio se caracteriza por la presencia de lavas de la Unidad Achiote de la fase temporal Paleo Poás, la cual fue descrita por Gazel y Ruiz (2005), Montes (2007) y Ruiz et al. 


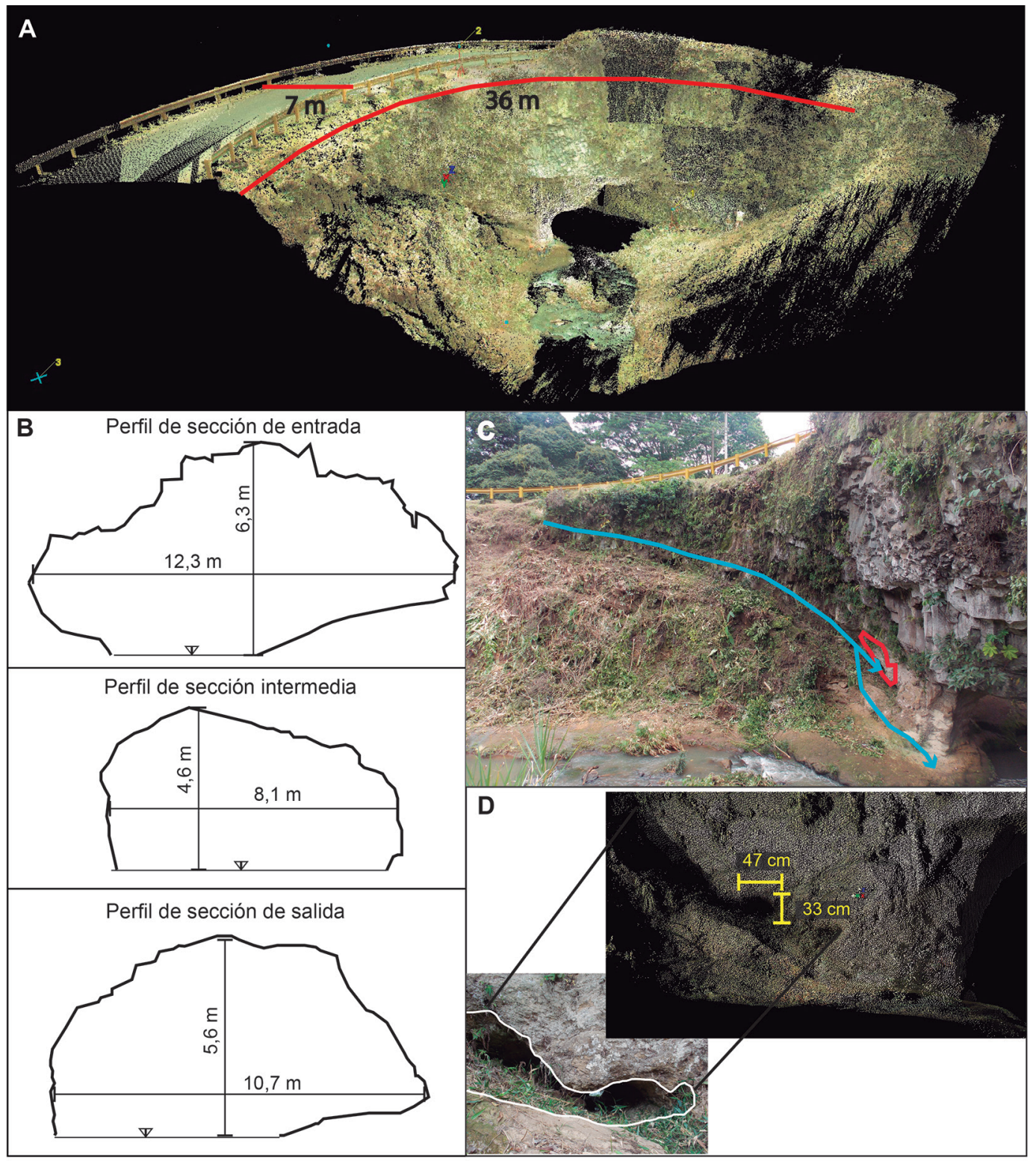

Fig. 3: A) Imagen lídar del Puente de Piedra, con las dimensiones de la parte superior. B) Perfiles de tres distintas secciones del arco. La sección intermedia es la que presenta la menor capacidad hidráulica de las tres. C) Orificio ubicado aguas arriba en la parte inferior del macizo al margen izquierdo del cauce, producido por la erosión hídrica sobre la unidad de tobas, que debido a su textura blanda y granulometría, el aporte de agua por las crecida del río y las aguas superficiales que descienden por el macizo provocan el lavado del material. D) Detalle del orificio con dimensiones $33 \mathrm{~cm}$ de alto y $47 \mathrm{~cm}$ de ancho, su mayor área se encuentra a los márgenes.

(2010), la cual consiste en un conjunto de coladas de lava andesíticas y basálticas de color gris con textura afanítica, fábrica masiva y presentan fracturamiento en lajas o en bloques métricos, producto de enfriamiento. Según las dataciones radiométricas ${ }^{40} \mathrm{Ar} /{ }^{39} \mathrm{Ar}$ (Ruiz et al., 2010), esta unidad tiene un rango de edad de $538-283 \pm$ $15 \mathrm{ka}$, estas lavas fueron datadas a una distancia 
aproximada del puente de $10 \mathrm{~km}$. Al norte del área de estudio y sobreyaciendo al resto de las unidades, se encuentra la Unidad de Tobas de Lapilli Poás, la cual según Gazel y Ruiz (2005), se extiende hasta cubrir las unidades lávicas del sector sur y suroeste del volcán Poás. Son depósitos que corresponden con tobas de lapilli fino a grueso, escoriáceo con líticos de lavas angulares. Presentan un color gris claro en su forma sana y colores naranja, café y morado en su condición meteorizada.

Localmente, el Puente de Piedra está compuesto por un flujo ignimbrítico. Este flujo presenta distintas facies de tobas: en la parte superior está constituido por una toba de flujo lítica soldada con disyunciones prismáticas y que se subdivide en tres unidades de enfriamiento. Estas unidades están sobreyaciendo una toba de flujo poco soldada que a su vez está sobre el basamento local constituido por brechas en la sección aguas abajo del Puente de Piedra y por depósitos lacustres en la sección aguas arriba de la estructura. (Fig. 4).

En la base del Puente de Piedra, se observa una brecha volcánica en el sector sur, aguas abajo y depósitos lacustres en el sector norte, aguas arriba. Sobreyaciendo estos materiales se encuentra un depósito laminado correspondiente con tobas de flujo, caracterizada como roca blanda con textura granular y muy meteorizada, con un espesor de $3,5 \mathrm{~m}$. Contiene fragmentos milimétricos de obsidiana de color negro y pómez de color blanca ambas muy alteradas con gradación inversa, dentro de una matriz de ceniza de color café. El contacto superior es gradacional con la ignimbrita columnar (Fig. 4).

El macizo superior corresponde con una roca piroclástica columnar fuertemente soldada de color gris oscuro, con textura eutaxítica granular, compuesta por material fino, líticos, pómez y fragmentos de obsidiana de tamaños milimétricos y formas angulares de alta esfericidad.

La toba lítica soldada tiene un espesor total de $7 \mathrm{~m}$ y se diferencian tres unidades de enfriamiento, donde la parte inferior forma columnas de 5 a 6 caras, la parte intermedia es blocosa y la superior es columnar con 4 a 6 caras, cubierta además por una capa de suelo originado por la alteración de las rocas (regolito) y depositación de cenizas más recientes (Figura 4).
Macroscópicamente esta roca piroclástica tiene una matriz de $90 \%$ de ceniza y cristales angulares de plagioclasa de tamaño milimétrico y $10 \%$ de fragmentos de lava con tamaños milimétricos que al meteorizarse presentan colores pardos. También contiene estructuras eutaxíticas de color amarillento. En la parte superior del flujo, las estructuras son granulares, gruesas y el tamaño de los fiammes de obsidiana es mayor, además se han observado fragmentos de madera en el techo del Puente de Piedra.

Según Pérez (2000), Mora et al. (2003) y Mora (2004), las rocas de Puente de Piedra pertenecen a la Formación Tiribí con edades de 0,32 - 0,33 Ma (Pérez et al., 2006), y procedente del volcán Barva. Sin embargo, según Alvarado (2015) y de acuerdo con dataciones de Alvarado y Gans (2012) las ignimbritas de esta zona provienen de la Paleo-Cordillera, con edades de 0,44 - 0,50 Ma. En el presente trabajo de acuerdo con las relaciones estratigráficas, se considera que Puente de Piedra podría tener una edad cercana a 0,5 Ma y que corresponde con el miembro intermedio de la Formación Colima, conocido como Puente Mulas, el cual según Ruiz et al (2010), en la sector sur del volcán Poás se presenta como ignimbritas con un espesor de hasta $20 \mathrm{~m}$. El volcán que dio origen a esta ignimbrita aún se desconoce y podría atribuirse al Poás o Barva hasta que se tenga mejores correlaciones estratigráficas y dataciones radiométricas de otros afloramientos de ignimbritas en la zona, incluyendo las del puente específicamente.

El edificio del volcán Poás se ha caracterizado por ser una zona sísmicamente muy activa. En los últimos dos siglos, fallas locales han originado terremotos históricos de magnitudes importantes (1772- M 5-6, 1888- ML 5,7, 1911- Ms $5,1,1912-$ Ms 5,1, 1955- Ms 5,5 y 2009-Mw 6,2) Montero et al. (2010). Algunos de estos sismos registraron daños en puentes, por las aceleraciones que ocasionaron el colapso de las estructuras y por los flujos de detritos que bajaron por los cauces. El terremoto de 1912, conocido como Terremoto de Sarchí, generó deslizamientos en las nacientes de los ríos Anonos y Sarchí que bajaron ocasionando daños en las partes bajas y en casas de diversos poblados ubicados en el sector suroeste del volcán 


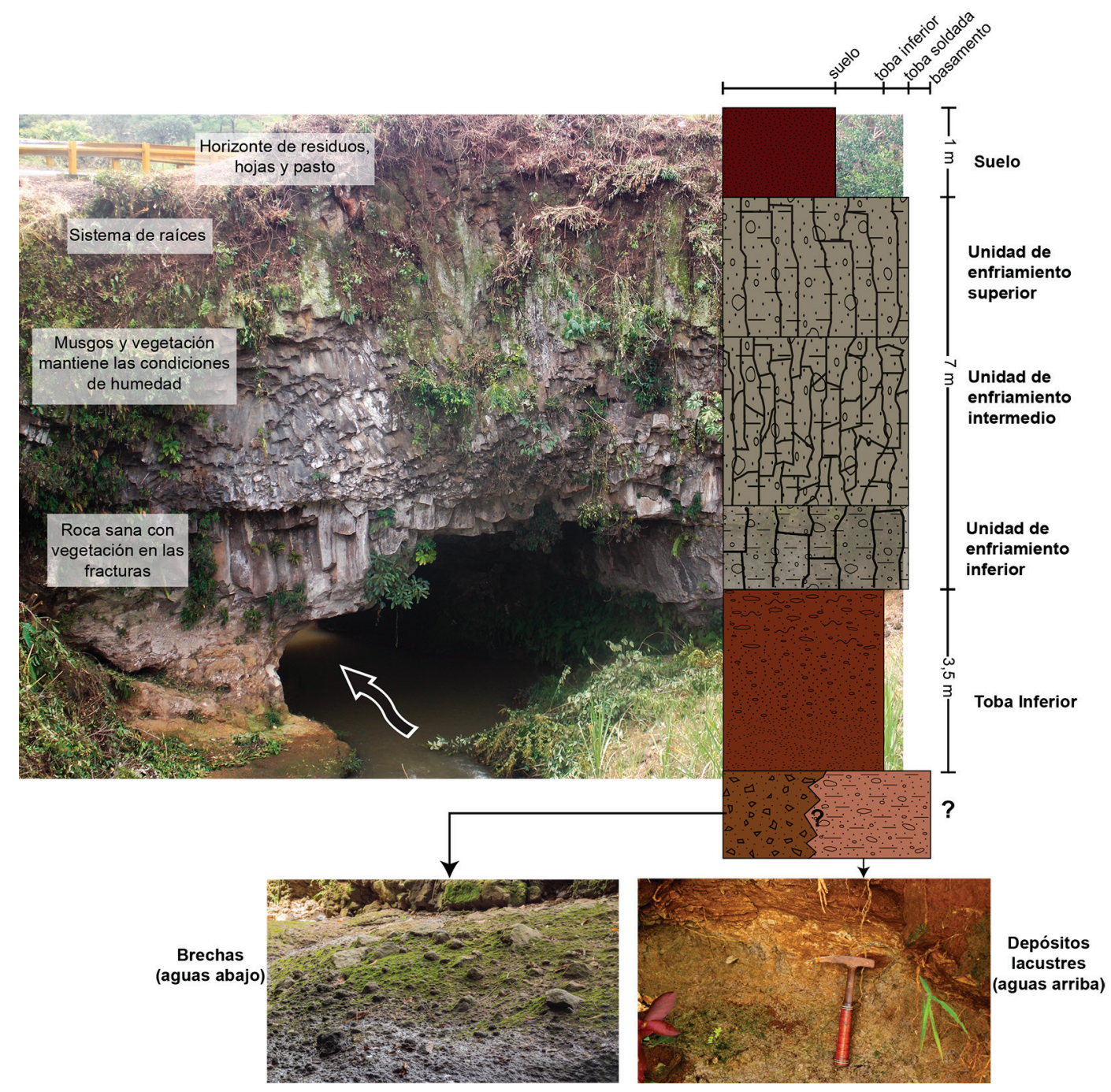

Fig. 4: Delimitación de las unidades de roca que constituyen el Puente de Piedra. La capa superior de suelo, es resultado de la meteorización de cenizas y la ignimbrita generada por las condiciones de humedad, temperatura y actividad biológica de insectos y plantas principalmente.

Poás, incluyendo la ciudad de Grecia (Alvarado et al., 1988). Existe la posibilidad de que un sismo similar se repita en las próximas décadas y pueda generar afectación en el Puente de Piedra, lo cual se tendrá que analizar en detalle en otros trabajos.

\section{Uso de la tierra}

La caracterización del uso de la tierra es importante para determinar los factores que pueden afectar el estado del puente a mediano y largo plazo, esto mediante la relación de estas actividades con el tráfico promedio diario que puede tener el puente. Para determinar el uso actual de la tierra, se tomó en cuenta la información disponible de PRUGRAM (2010) y las imágenes aéreas de Google Earth desde el 2009 hasta la fecha (Fig. 2C).

De acuerdo con el uso de la tierra en las áreas periféricas y los cambios que puedan existir, eso puede afectar la dinámica de los vehículos que utilizan el puente, ya sea por peso o frecuencia 
de uso. Aquí trabajamos bajo la premisa de que un incremento del paso de vehículos más pesos y de frecuencia de uso, podría tener efectos negativos en la estabilidad del puente. Esto ocurriría si hay un aumento del área de la tierra destinada a urbanismo $\mathrm{u}$ otras actividades que necesiten transporte de carga pesada como industria o extracción de áridos.

Según los datos de PRUGRAM (2010), el uso de suelo de la zona mostrada en la figura $2 \mathrm{C}$, tradicionalmente ha correspondido con sembradíos de caña de azúcar y café, en un $34 \%$ y un $31 \%$ respectivamente, y el $4 \%$ corresponde a otros cultivos. Las zonas de cultivo de estos productos se encuentran dentro de los valles fluviales y las zonas de pendiente moderada. Se considera que este tipo de actividad representa un impacto medio al puente debido a la afluencia baja a media de transporte de carga con pesos estimados entre 4 y 6 toneladas, que atraviesa el puente y la alteración en los sistemas de drenajes (Fig. 2C). En los últimos diez años, en la zona de estudio se ha dado un proceso de cambio paulatino del uso de la tierra, pasando de núcleos urbanos relativamente pequeños y dispersos, y zonas agrícolas a proyectos habitacionales de densidad media. De modo que actualmente se utiliza un $12 \%$ de los terrenos en áreas urbanas y en los próximos años podría aumentar. Consideramos que estas zonas urbanizadas representan un impacto medio en la zona, ya que puede generar problemas que afecten directamente el puente, por ejemplo: un aumento en la cantidad de vehículos livianos (entre 1 y 2 toneladas) que transitan sobre la estructura y además la impermeabilización de los suelos por paso de uso de suelo de agrícola a urbanizado; generando mayor escorrentía y aumentando el caudal de los ríos de la zona, lo que podría ocasionar problemas de mayor erosión en la estructura.

Las zonas boscosas, que constituyen un $10 \%$, representan un impacto positivo para la estructura, debido a que se ubican a largo de los márgenes de los ríos y disminuyen la escorrentía y la erosión. Se considera que la presencia de sitios de extracción de materiales áridos en la zona representa un factor negativo y de alto impacto en la estructura del puente, por el aumento en la cantidad de transporte pesado al que es sometido (entre 10 y 12 toneladas), y los efectos que puede generar como vibraciones, ocasionando un desgaste acelerado, además de la remoción de la cubierta natural que evita la erosión y escorrentía. Por lo tanto, se recomienda que no se use el puente como ruta de paso para este tipo de vehículos cargados.

\section{MECANISMO DE FORMACIÓN DE PUENTE DE PIEDRA}

Los pobladores del cantón de Grecia creen que el puente tiene un origen sobrenatural, la leyenda de como se formó este puente incluye al diablo y un campesino de la zona, según relata Zeledón, 2000. En este trabajo explicamos de forma científica como se pudo dar origen a esta morfología aunque la leyenda tradicional se debe de preservar y explotar para atraer a los visitantes.

La formación del Puente de Piedra se puede explicar de la siguiente manera: Originalmente en la zona debió de existir un cañón o depresión fluvial. En algún momento hace unos 0,44-0,50 Ma inicia con una voluminosa erupción volcánica de la Paleo-Cordillera provocando un flujo piroclástico. Los materiales de este flujo ignimbrítico una vez depositados, presentan diferentes facies de consolidación y de velocidad en su enfriamiento, esto generó un depósito ignimbrítico compuesto por una toba masiva poco soldada en la parte inferior y una toba lítica soldada con tres diferentes unidades de enfriamiento distinguible por sus diaclasas en la parte superior. Estos depósitos piroclásticos rellenaron la paleotopografía, posteriormente por el agua de escorrentía se generaron nuevos drenajes que erosionaron y profundizaron las tobas soldadas hasta llegar a la capa de tobas sin soldar en la parte inferior. La dinámica hidráulica sobre la capa de tobas inferiores fue socavando esta sección progresivamente hasta lograr atravesarla. Con el tiempo, el agua siguió fluyendo por ese orificio, en un proceso abrasivo que lo fue ensanchando y que continua hasta el día de hoy.

En general, para la formación de los puentes o arcos de piedra, todos los procesos involucran la acción del agua, gravedad, variación de temperatura o la presión tectónica a la roca en un periodo de miles de años y se pueden dar de manera macroscópica y microscópica. 


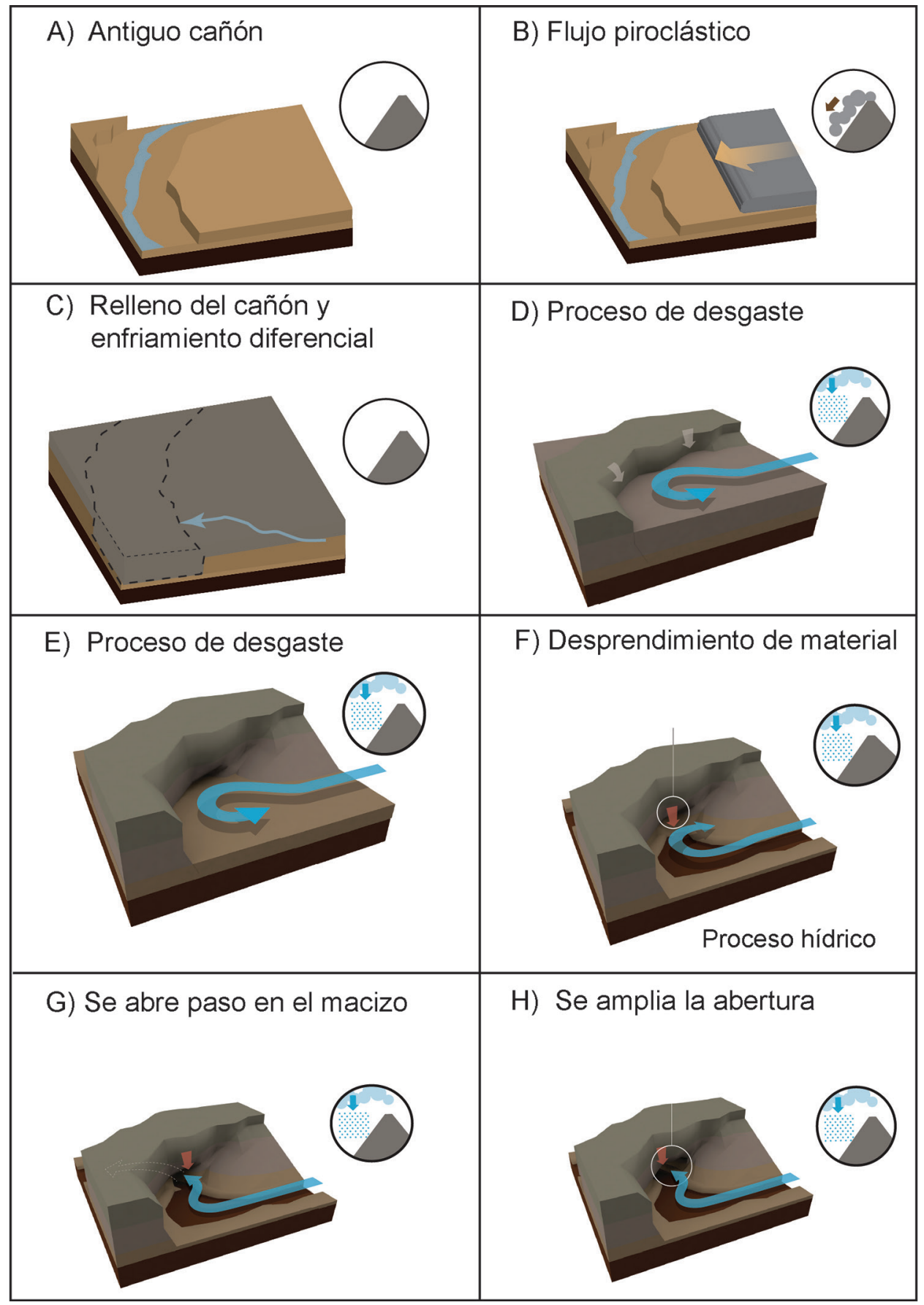

Fig. 5: Sucesión de eventos de la posible formación del Puente de Piedra. Formación de las tres unidades de enfriamiento y proceso de erosión fluvial la cual finaliza con la abertura del agujero. Imágenes realizadas por Daniel Solano. 
Macroscópicamente ocurre cuando las fracturas generan varios fragmentos que se pueden mover relativamente entre ellos por las fuerzas de gravedad o la presión del agua, en un periodo de miles de años. La erosión microscópica ocurre cuando procesos químicos disuelven o dislocan la matriz vítrea y cristalina, destruyendo y dispersando los granos sueltos (Wilbur, 2003).

Según Mora (2004), el Puente de Piedra se ha clasificado como un puente natural meándrico, ya que el mismo se asocia con una corriente fluvial activa. La característica plana de la parte superior del dintel y arqueado en su parte inferior, recuerda un puente construido por los seres humanos. Los procesos descritos por Wilbur (2003) que pudieron haber ocasionado la erosión diferencial en Puente de Piedra, son los siguientes: meandro inciso o cortado, corriente lateral o subterránea, expansión horizontal y vertical, colapso de la cavidad, techo o paredes.

De acuerdo con Wilbur (2003) aunque el agua que fluye en el lecho del río desempeña un papel importante en la formación de este tipo de arco natural, no es el único proceso de erosión de involucrado, también puede ocurrir un colapso de la pared, dando paso a una abertura semicircular. $\mathrm{Su}$ formación comienza cuando un meandro genera una incisión en la roca como resultado de la elevación rápida y la erosión que la afecta. Esto resulta en un cuello delgado en la pared de roca que separa dos corrientes de agua que fluyen. Una vez que la acción de la corriente ha incidido suficientemente la roca, se puede producir el colapso de la pared. En ese punto, las inundaciones ocasionales desencadenan que la corriente fluya eventualmente a través de la abertura. El desarrollo posterior, se debe a un mayor colapso de la pared a la intemperie y el fortalecimiento de la compresión, además si es o no una corriente continúa fluyendo a través de la abertura.

En algunos casos, la corriente fluye en el pie de uno de los pilares, ocasionando la ampliación de ese extremo de la abertura. Por esta razón es habitual que la abertura pueda expandirse en todas las direcciones lejos de la corriente que fluye a través de él, como en el caso del margen izquierdo del Puente de Piedra. Este proceso continúa hasta que o bien el dintel se vuelva incapaz de soportar su propio peso o uno de los pilares se vuelve demasiado delgado para soportar el peso del dintel. Estos son los indicadores observables de madurez, ya que un puente natural meándrico es joven si la corriente sólo fluye a través de la abertura en una inundación, o si la corriente cubre el suelo de la abertura. Si al menos uno de los pilares se oculta de manera significativa desde el lecho del río, se puede considerar adulto, ya que tiene una corriente constante bajo ella y oculta parte de las paredes, como lo es el Puente de Piedra.

\section{PUENTE DE PIEDRA DESDE EL PUNTO DE VISTA INGENIERIL}

Se hace la comparación del puente de origen natural con una estructura creada por los humanos para entender su estructura, comportamiento y estabilidad, haciendo una correlación con una estructura que entendemos de mejor manera.

Según la Asociación Estadounidense de Oficiales de Carreteras y Transportes Estatales (2012) AASHTO por sus siglas en inglés (American Association of State Highway and Transportation Officials), un puente es cualquier estructura con una abertura mínima de $6,1 \mathrm{~m}$, que forma parte de una carretera, ya sea que esté situada arriba o debajo de él. Además un puente, está normalmente diseñado para no ser alcanzado por el agua, incluso en el caudal máximo esperado en el río.

De acuerdo con el Ministerio de Obras Públicas y Transportes (MOPT, 2007) un puente debe tener los siguientes componentes: a) superestructura, b) subestructura y c) accesorios (Figura 6).

Según con el concepto mencionado, el Puente de Piedra es considerado como un puente desde el punto de vista ingenieril, ya que cumple con los requisitos, al tener un ancho de abertura máximo de 10,7 m en la sección de salida y la presencia de 


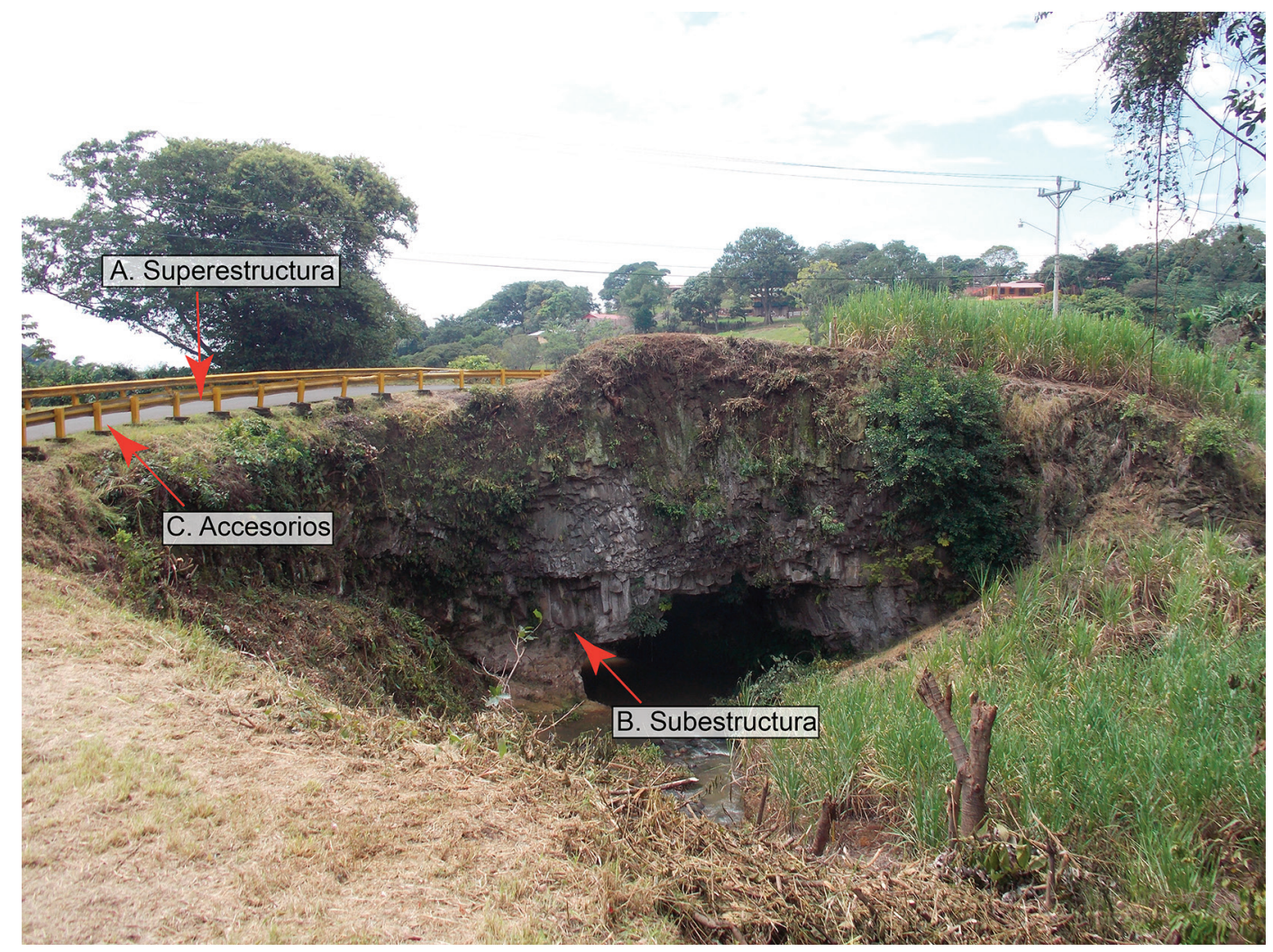

Fig. 6: Componentes observables. a) Superestructura, compuesta por el piso, los elementos principales (vigas, cerchas y arco) y los elementos secundarios (diafragmas, sistemas de arriostramiento, portales, aceras). b) Subestructura, emprende los apoyos, los bastiones y las pilas. c) Accesorios, elementos sin función estructural pero vital para garantizar el buen funcionamiento del puente tales como superficie de rodamiento, barandas y juntas de expansión.

los accesorios necesarios para la seguridad vial, además de la superestructura y subestructura. También se puede identificar como un puente tipo arco de mampostería de piedra, y de tipo vial, ya que en la parte superior es utilizado para el paso de vehículos de un solo carril.

Desde el punto de vista geológico, según Wilbur (2003) y Mora (2004), un puente natural es un tipo de arco natural donde una corriente de agua ha sido el agente principal en la formación del agujero. Por lo tanto, el Puente de Piedra también cumple con los atributos requeridos para ser considerado un puente natural.

A pesar de que se trata de una estructura construida por procesos naturales, ha servido de base para el paso de una carretera cantonal y contiene los componentes necesarios para que este sea transitable. El análisis de esta estructura difiere en que se trata de un macizo rocoso continuo lateralmente y en sus márgenes, por lo que los esfuerzos que normalmente se concentran en una estructura limitada, ahora se propagan de manera indefinida hasta que haya un cambio lateral de litología.

\section{ANÁLISIS Y EVALUACIÓN DEL PUENTE DE PIEDRA}

Anteriormente, se realizó un análisis geotécnico de Puente Piedra (Mora et al., 2003), donde se indicó que la condición del puente en ese momento, desde el punto de vista de la resistencia de la toba inferior, era segura, pues el factor de seguridad que se determinó fue superior a un valor de 2,5. También se realizó una evaluación de la calidad del macizo rocoso fracturado sobre la toba 
soldada, este se clasificó como pobre, de acuerdo con el sistema RMR, y muy pobre según el sistema Q. Para el presente trabajo se realizaron los mismos estudios con el fin de compararlos y poder determinar si en los últimos 13 años las condiciones valoradas en el estudio de Mora et al., 2003 había variado o se han mantenido. Los resultados de nuestro análisis muestran diferencias mínimas con los datos del año 2003, sin embargo sí se observaron algunos deterioros que no habían sido reportados antes. En este trabajo, el análisis de las condiciones actuales de la estructura se realizó en tres secciones (Fig. 7): Aguas arriba del puente o sector norte, aguas abajo o sector sur y lo que corresponde con la sección central que incluye un análisis de la parte de abajo del arco de piedra y la sección superior del puente que está cubierta por asfalto.

\section{Sección aguas arriba}

El río Poró es un río de montaña con una pendiente moderada de aproximadamente $>8^{\circ}$, que presenta un comportamiento de tipo meándrico, especialmente unos $500 \mathrm{~m}$ antes de llegar a la zona del Puente de Piedra, donde el curso del río tiene cambios bruscos de dirección. Algunos de estos cambios de dirección son de casi $70^{\circ}$, aunque, también se observaron otros menos bruscos con ángulos entre $30-45^{\circ}$. Estos cambios hacen que sus aguas se observen con un flujo de tipo turbulento y esto origina en sus laderas zonas de erosión y frente a ellas zonas de depositación.

En las zonas de erosión se dan procesos de socavación, debido a la dinámica del flujo que trae el agua y la turbulencia que se genera al golpear la superficie con un ángulo $>45^{\circ}$. Los materiales removidos se depositan en las zonas donde la energía de las aguas es menor, usualmente esto ocurre en zonas relativamente planas que se ubican perpendicularmente frente a los sitios de erosión (Fig. 8).

Es usual que en los ríos de la zona durante la estación lluviosa (entre mayo y noviembre), aumenten su caudal y el área de afectación por los procesos erosivos fluviales también aumenta, especialmente durante crecidas relacionadas con tormentas torrenciales. La energía del agua puede aumentar y acarrear materiales (rocas, troncos, basura) que contribuyen a una mayor erosión en las laderas fluviales (Fig. 8).

Los cambios de dirección de flujo y el carácter meándrico del río Poró afectan directamente el Puente de Piedra en dos sitios aguas arriba. Primero, en la zona inferior izquierda de la entrada del arco y segundo, en la parte inferior interna del arco (Fig. 8).

En la sección aguas arriba del Puente de Piedra se identificó un daño puntual importante por erosión directamente en el pie de la estructura en su lado izquierdo. Se trata de un orificio que atraviesa de lado a lado el macizo rocoso, formando un pequeño arco de $47 \mathrm{~cm}$ de alto, 33 $\mathrm{cm}$ de ancho y $6,3 \mathrm{~m}$ de largo (Fig. 3C). Se interpreta que las aguas superficiales de los drenajes que discurren hacia la margen izquierda y al pie del macizo, ejecutan un proceso de erosión hídrica sobre la toba inferior; esta ruta que tienen las aguas de escorrentía facilita el crecimiento de un orificio. Este orificio no fue descrito en el trabajo de Mora et al. (2003), por lo que se considera que su formación es de la última década. Este problema de erosión hídrica, de no tratarse adecuadamente y en forma oportuna, es probable que el orificio en la unidad de toba inferior se expanda y se una con el arco principal haciéndolo más amplio. Esta nueva condición podría propiciar el colapso de segmentos del techo en la unidad de las tobas soldadas.

\section{Sección superior, inferior y central de la estructura}

Se examinaron los problemas encontrados sobre y bajo la parte central del Puente de Piedra. Las capas naturales que constituyen los niveles superiores del puente son regolitos y cenizas, los cuales están expuestos directamente a los factores atmosféricos que promueven la generación de suelo. En ambientes tropicales, la profundización de la meteorización de la roca se ve favorecida por la cantidad de lluvia (3000 - $4000 \mathrm{~mm} / \mathrm{año})$ y las altas temperaturas $\left(25-30^{\circ} \mathrm{C}\right)$, también por los procesos biológicos como: el crecimiento de 


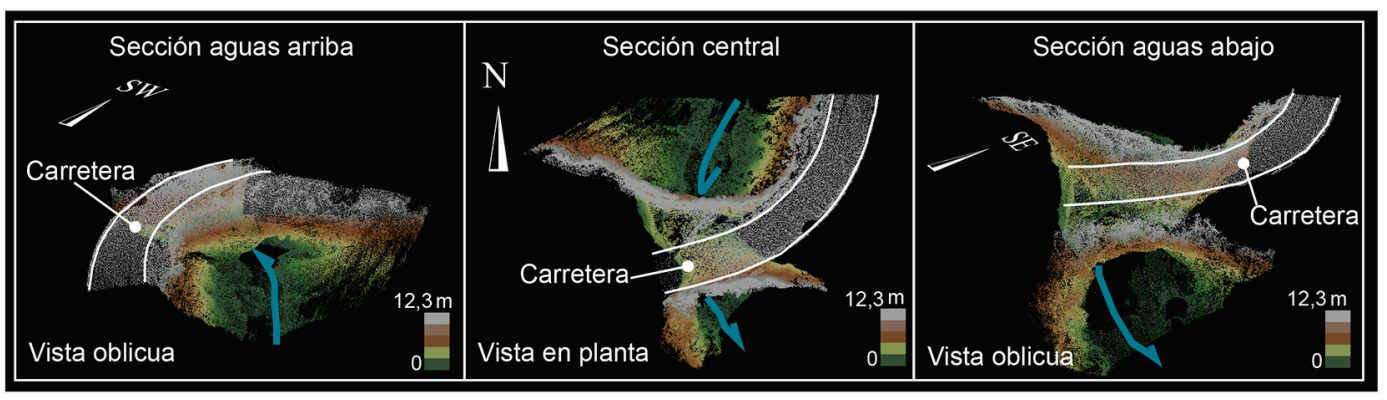

Fig. 7: Se muestran los modelos de elevación digital de las secciones del Puente de Piedra levantadas con el escáner lídar y que fueron analizadas en detalle en este trabajo.

la vegetación, la profundización de las raíces y oxigenación de suelos y roca por medio de insectos. Además, la meteorización química depende del tipo de roca, la erosión y el clima, donde las fracturas, junto con la disolución de minerales pueden aumentar la permeabilidad, acelerando el desgaste del macizo, y que al permanecer a una zona crítica tropical el espesor del suelo originado va a ser mayor comparada con una zona no tropical (Mana et al. 2015). Con respecto a los suelos, de acuerdo con el mapa de clasificación de suelos en el cantón de Grecia de Montes (2007), la zona del Puente de Piedra corresponde con la unidad informal Rosales, que corresponden a suelos con granulometría fina, donde predominan los limos. Esta zona se clasifica como suelos poco permeables, con poca conductividad hidráulica y menor potencial de infiltración, lo que provoca un aumento de escorrentía superficial, además presenta plasticidades varían entre alta, muy alta e intermedia.

En la zona inferior del arco (bajo el puente), se encuentra la toba soldada columnar que forma el techo del arco, en las paredes de la margen izquierda presenta una mayor vulnerabilidad estructural que el margen derecho. Esto debido a que el lado izquierdo presenta una morfología más esbelta en la sección que corresponde a la unidad de toba inferior (Fig. 9). Este sector está siendo erosionado y afectado directamente por la erosión fluvial tanto de las aguas del río como del drenaje que baja por el costado de la estructura.
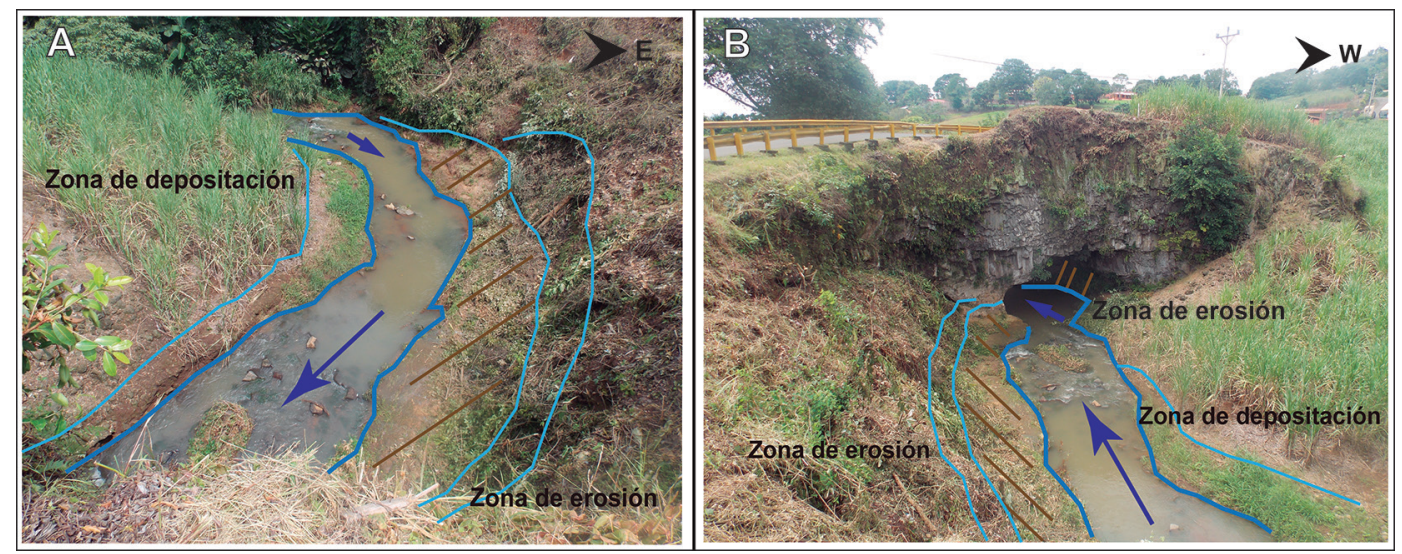

Fig. 8: A) y B) Vista del Río Poró aguas arriba del Puente de Piedra, con vista desde el puente. Se observa el cambio de dirección del curso del río, que origina zonas de erosión y zonas de depositación. Hay dos zonas de erosión que están afectando directamente el puente, en la margen izquierda y la margen derecha dentro del arco del puente. 
La margen derecha del arco es más robusta con casi $6 \mathrm{~m}$ en la base. Sin embargo, también se encuentra erosionada en la parte inferior que corresponde con la unidad de tobas, ya que recibe el impacto frontal del agua. La unidad de tobas soldadas presenta fracturas verticales y algunas horizontales (Figura 10).

En la salida del arco aguas abajo, el principal problema es el crecimiento de vegetación entre las columnas de la unidad de ignimbritas. Las raíces van ensanchando los espacios entre las columnas hasta provocar el colapso. Las tobas están erosionadas por plantas, insectos y vandalismo.

Sobre el asfalto de las aproximaciones del puente y la superficie de ruedo, se encontraron defectos que facilitan la infiltración de agua y que posteriormente afectarán en el macizo rocoso: huecos en el asfalto, bacheos mal elaborados, piel de lagarto, baches sobre zonas con piel de lagarto, fisuras de borde por falta de confinamiento que originan una pérdida de soporte del material, desprendimiento de asfalto y descalzamiento al borde de la superficie de ruedo que se encuentra con un nivel de severidad media.

Hay problemas de drenajes y manejo de aguas de lluvia sobre el puente que pueden afectar la roca, como el hecho de que no existe un sistema que conduzca el agua pluvial de manera adecuada. Lo que ocurre actualmente es que el agua baja directamente sobre el macizo rocoso y está contribuyendo con la erosión.

Con respecto a la seguridad vial del puente, se pueden mencionar algunos problemas (Fig. 11): no hay aceras para peatones y solo existe un pequeño espacio donde crece vegetación como pasto y maleza entre la guardavía y la carretera; en el sector oeste del puente hay un montículo de suelo y rocas que impide la visibilidad de los usuarios de la vía hacia el otro lado del puente, y la situación se agrava al ser un puente en curva; el guardavía a ambos lados de la calzada no tiene un abatimiento apropiado; los postes metálicos que la sostienen están mal utilizados; el guardavía que está localizada aguas arriba, está dañado por impactos y debería ser sustituido; falta de iluminación pública adecuada; hay postes metálicos de publicidad al lado de la vía que podrían ser un obstáculo visual para los usuarios; no existe demarcación horizontal sobre la superficie de ruedo; el puente solo tiene espacio para que circule un vehículo en un sentido a la vez, pero en ocasiones es utilizado como doble vía, debido a que los usuarios no pueden ver si hay otro vehículo en la vía por la falta de visibilidad que genera el montículo antes mencionado.

Del escaneo lídar que se realizó en el Puente de Piedra, se extrajeron tres cortes de la zona por donde atraviesa el agua (secciones de entrada, intermedia y de salida; Fig. 3B). Los resultados muestran que el perfil de la sección de entrada tiene las dimensiones máximas en comparación con las otras dos secciones, con un ancho de 12,3 m, una altura de $6,3 \mathrm{~m}$, y un área de $58,74 \mathrm{~m}^{2}$. El perfil de la sección intermedia presenta las dimensiones más reducidas de las tres: $8,1 \mathrm{~m}$ de ancho, 4,6 $\mathrm{m}$ de alto y un área de $38,34 \mathrm{~m}^{2}$. Las dimensiones del perfil de la sección de salida son: $10,7 \mathrm{~m}$ de ancho por 5,6 $\mathrm{m}$ de altura, con un área de 55,35 $\mathrm{m}^{2}$. Con base en esta información, se considera que durante las crecidas del río Poró, las paredes de la sección intermedia son las que podrían presentar mayor desgaste por la erosión fluvial.

\section{Sección aguas abajo}

En esta sección, el principal problema que se identificó al igual que en otras secciones del puente, es el crecimiento de vegetación entre las columnas de la unidad de tobas soldadas. El crecimiento de la raíces ensancha los espacios de las diaclasas, además la descomposición de materia orgánica puede generar ciertos ácidos que facilitan la alteración de la roca y favorecen la erosión. La vegetación puede producir caída de rocas de todos los tamaños.

Además, debido al fácil acceso que tienen las personas a este sector del puente, se observó vandalismo (tallado de rocas) en la unidad de tobas.

\section{Tránsito promedio diario sobre el Puente de Piedra}

Para obtener los datos del tránsito promedio diario (TPD) sobre el Puente de Piedra, se realizó un conteo de tránsito de vehículos, mediante 


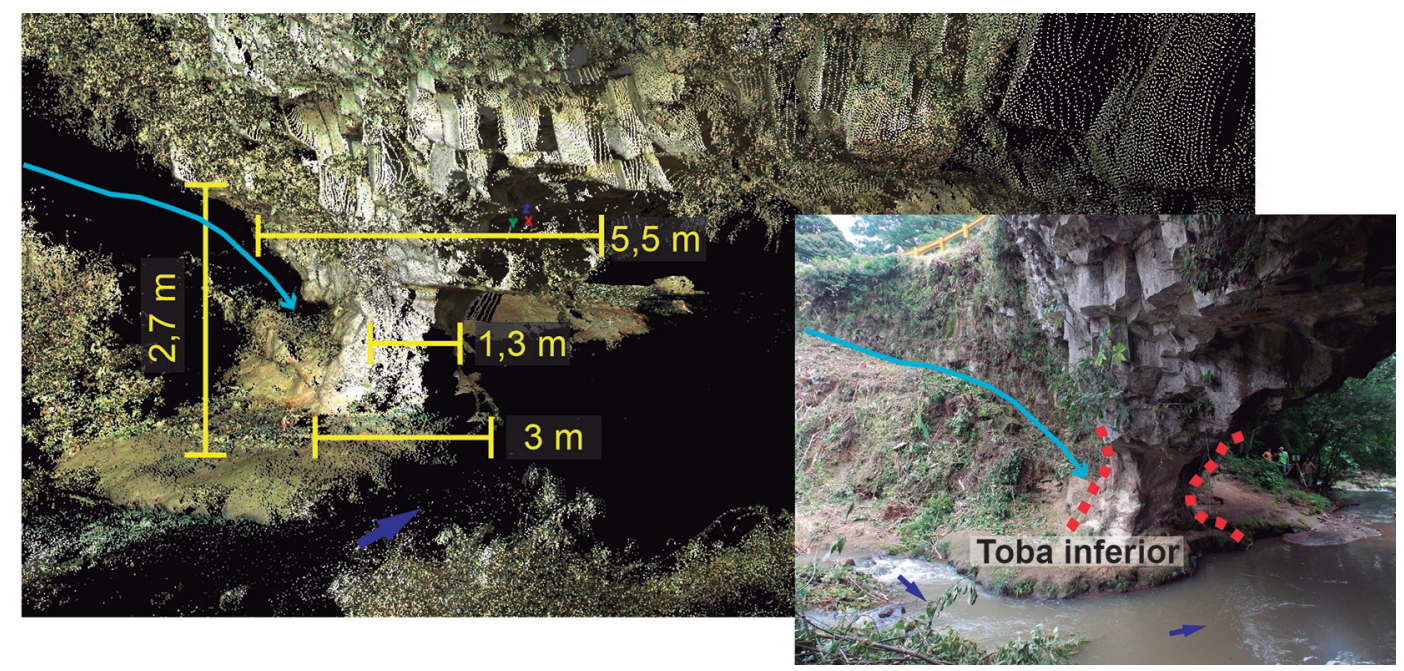

Fig. 9: Adelgazamiento en el margen izquierdo, debido a la erosión del río y la escorrentía que desciende por los márgenes del macizo que afectan directamente a la unidad de tobas inferior.

un contador electrónico que se colocó sobre la estructura. Los datos presentados en el cuadro 2 representan una muestra de 24 horas por día entre el 21 y 29 de octubre del 2014.

De los datos recolectados, se concluye que la gran mayoría de los vehículos que transitan sobre el puente corresponden a automóviles livianos en un $81,03 \%$, seguido por las motocicletas con $13,6 \%$ y solamente un $5,37 \%$ corresponden con automotores pesados: C2 (camión de dos ejes), bus $\mathrm{C} 2+$ (bus con eje simple trasero), C3 (camión de tres ejes), T3 S2 (tractor-camión con semirremolque). El promedio del TPD que transitan por el puente es de 2576,8 vehículos por día, correspondiente con bajo volumen vehicular. Estos datos son congruentes con lo observado en el sitio e indican que la cantidad de vehículos es relativamente baja. Los vehículos pesados son en su mayoría autobuses, y su flujo es limitado y esporádico. Estos datos serán muy útiles para realizar comparaciones dentro de varios años y correlacionarlos con el cambio de uso de la tierra de la zona.

Según el Padrón Minero de la Dirección de Geología y Minas de Costa Rica, en un radio de 2 $\mathrm{km}$ de distancia del puente, hay dos concesiones de extracción de materiales, por lo tanto es muy probable que parte de los vehículos pesados registrados correspondan con vagonetas que acarrean materiales extraídos de estos tajos.
Al no existir datos de TPD previos a este trabajo, no es posible realizar una comparación estadística en función del tiempo. Sin embargo, según la percepción de los vecinos y por un aumento en la población de la zona, se considera posible que en los últimos diez años el TPD de la zona haya presentado un incremento notable. Pese a este posible incremento, los valores actuales siguen siendo bajos, aún para una ruta cantonal. No obstante, se considera que es importante que se hagan más análisis de este tipo en el futuro y que se tome en cuenta esta ruta dentro del plan regulador del Cantón de Grecia y las implicaciones que este podría tener en el tránsito sobre la vía y el puente.

\section{GEOPARQUES Y POTENCIAL TURÍSTICO DE PUENTE DE PIEDRA}

El Parque Nacional Volcán Poás, es el área silvestre protegida que recibe la mayor afluencia de visitantes en Costa Rica y América Central, y uno de los sitios turísticos más importantes de Latinoamérica (SINAC, s.f.). Solamente en el año 2010 se reportaron casi 250000 visitantes y se estima que este número se ha mantenido con tendencia a la alza en los últimos años (Quiros, 2014). Para poder atender de la mejor forma a este gran número de personas, las condiciones 


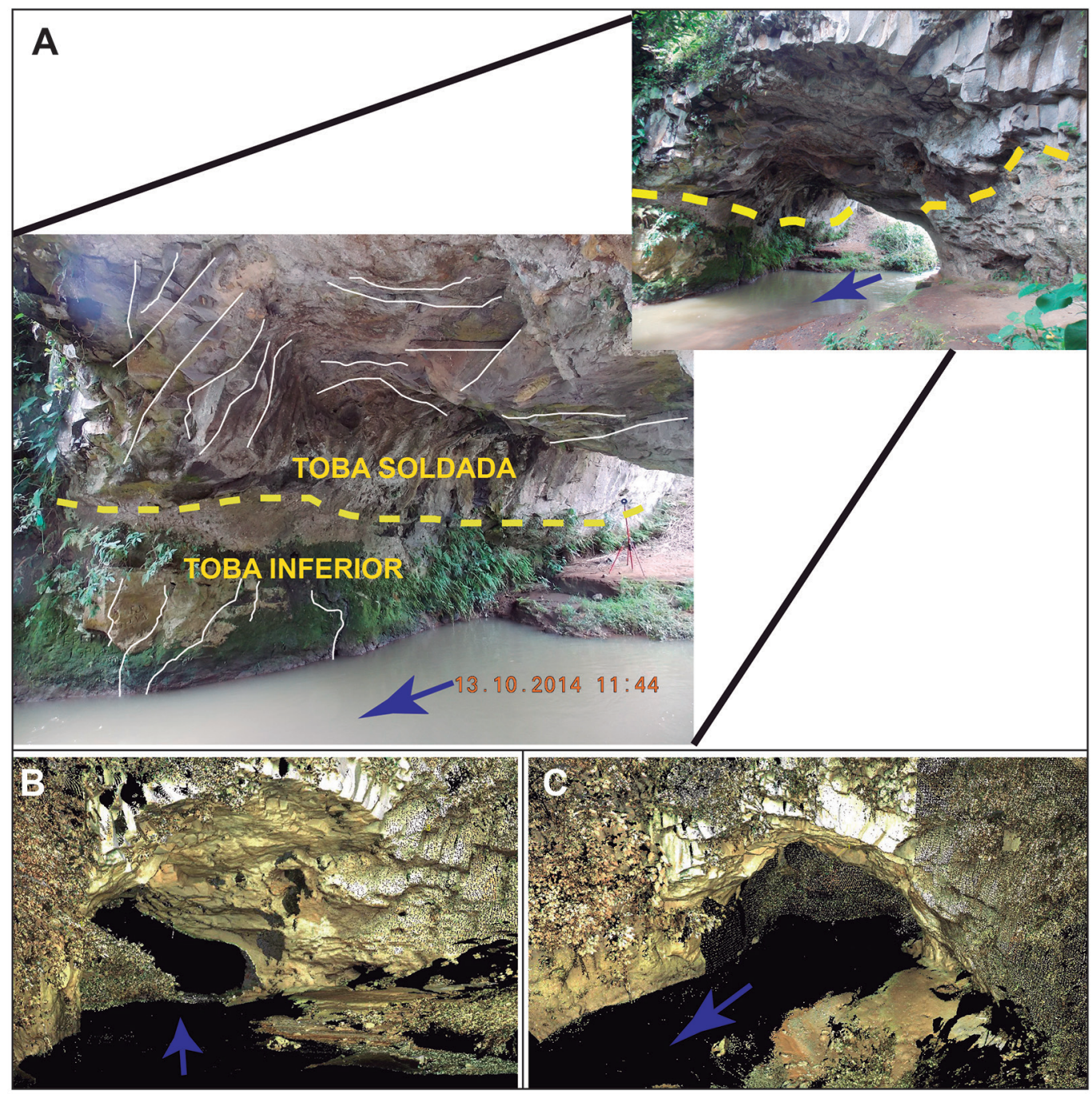

Fig. 10: A) En la unidad de tobas inferior y tobas soldadas se observa el crecimiento de vegetación que favorece la meteorización física y posteriormente la remoción de materiales. Además se observan fracturas casi verticales que favorecen el corte de la pared mientras que en la unidad de tobas soldadas localizadas en el techo las fracturas horizontales son provocadas por la descompresión. B) Imagen lídar de la entrada al arco. C) Imagen lídar de la salida del arco.

de la infraestructura que reciben a los visitantes, así como la oferta turística tienen que ser óptimas y variadas. En esta sección mencionamos los esfuerzos que se han realizado para mejorar la infraestructura de la zona del volcán Poás y como se podría diversificar la oferta turística incluyendo lugares que han pasado casi desapercibidos pese a su gran potencial, importancia geológica y belleza escénica como lo es el Puente de Piedra. Este sitio se puede desenvolver como una oferta de ecoturismo, el cual de acuerdo con CANAECO (2004) el ecoturismo es aquel segmento especializado del turismo responsable, que promueve y apoya la conservación de la naturaleza y los valores culturales de los destinos, los interpreta para el cliente, favorece el mejoramiento socioeconómico de las comunidades locales y que persigue sensibilizar y satisfacer, de manera ética, a los clientes. Mantiene sus actividades con un diseño y a una escala apropiada al entorno y 
Cuadro 2

Datos de tránsito promedio diario (TPD) sobre el Puente de Piedra entre el 22 y el 26 de octubre del 2014.

\begin{tabular}{cccccccc}
\hline \multicolumn{2}{c}{ Puente de Piedra } & Livianos & Motos & C2, Bus, C2+ & C3 & T3, S2 & Pesados \\
\hline Fecha & TPD & \multicolumn{7}{c}{ Porcentaje (\%) } & \\
\hline $22 / 10 / 2014$ & 2739 & 80,32 & 13,65 & 5,29 & 0,47 & 0,26 & 6,02 \\
$23 / 10 / 2014$ & 2831 & 78,95 & 14,45 & 5,86 & 0,42 & 0,32 & 6,61 \\
$24 / 10 / 2014$ & 2779 & 80,60 & 12,41 & 5,90 & 0,40 & 0,68 & 6,98 \\
$25 / 10 / 2014$ & 2621 & 81,11 & 13,89 & 4,39 & 0,31 & 0,31 & 5,00 \\
$26 / 10 / 2014$ & 1914 & 84,17 & 13,58 & 1,72 & 0,21 & 0,31 & 2,25 \\
Promedio & 2576,8 & 81,03 & 13,60 & 4,63 & 0,36 & 0,38 & 5,37 \\
\hline
\end{tabular}

pone a sus clientes en contacto directo y personal con la naturaleza y la cultura local.

La estrategia que utilizamos en este análisis está enfocada en ver la infraestructura y la oferta turística más allá de los límites del parque nacional como un aspecto fundamental para el adecuado funcionamiento del sistema volcán-turismodesarrollo. Es por esta razón que dentro de este tipo de obras de infraestructura se incluyen: carreteras, puentes, centros de visitantes, museos, senderos, baños públicos, restaurantes, tiendas, parques de recreación, entre otras. Estas obras deben estar presentes no solo en el área de los cráteres en la cima si no en todos los sitios turísticos que existen en los flancos del volcán Poás.

Para que toda esta infraestructura se encuentre en estado óptimo y se pueda desarrollar aún más, los fondos gubernamentales parecen no ser suficientes y por lo tanto se requieren otras fuentes de inversión y financiamiento. Este puede ser aportado por inversionistas locales, extranjeros, municipales, estatales o hasta por entes de financiamiento internacional como por ejemplo el Banco Interamericano de Desarrollo (BID). Esta última entidad internacional junto con una partida estatal está actualmente desarrollando un proyecto de 1,36 millones de dólares en mejoras de infraestructura, que incluye accesos y planes de turismo que vinculan a comunidades cercanas a áreas silvestres protegidas. Sin embargo, la mayoría de los trabajos se han enfocado en la zona de los cráteres y dentro de los límites del parque nacional.

Con respecto a la infraestructura vial de la zona, después del Terremoto de Cinchona (6,2
Mw) en el año 2009, se ha trabajado en recuperar rutas nacionales y cantonales que dan acceso a la cima del volcán Poás y sus alrededores, como las rutas No 120, 126 y 146, específicamente en los tramos entre Vara Blanca y San Miguel de Sarapiquí así como también el sector de Cartagos, Fraijanes y Poasito entre otras. Sin embargo, falta aún mayor señalización en esas rutas así como inversión en otras rutas nacionales como la No. 708 que comunica la zona de Sarchí con Bajos del Toro y otras más ubicadas en el sector noroeste del volcán Poás. Los fondos que se han utilizado para estos proyectos de rehabilitación han provenido de la Comisión Nacional de Emergencias y del presupuesto anual del Ministerio de Obras Públicas y Transportes. Dentro del mismo proyecto del BID mencionado anteriormente, se incluye la ampliación y construcción de un nuevo espacio para estacionamiento de buses dentro del parque nacional. La recuperación de las vías de transporte de la zona, favoreció la recuperación económica y mayor dinamismo después del Terremoto de Cinchona. Sin embargo, debido al cierre del parque nacional por las erupciones que ha presentado el volcán Poás a partir de abril del 2017, el turismo en la zona se ha visto nuevamente afectado, así como parte de la inversión que se realizó principalmente en la zona del mirador y senderos. De mantenerse cerrado el parque nacional por un periodo extenso y un aumento de la actividad volcánica, esa inversión se podría perder por completo. Debido a este situación, se podría considerar que hubiera sido mejor invertir en infraestructura de sitios alternativos al sector 

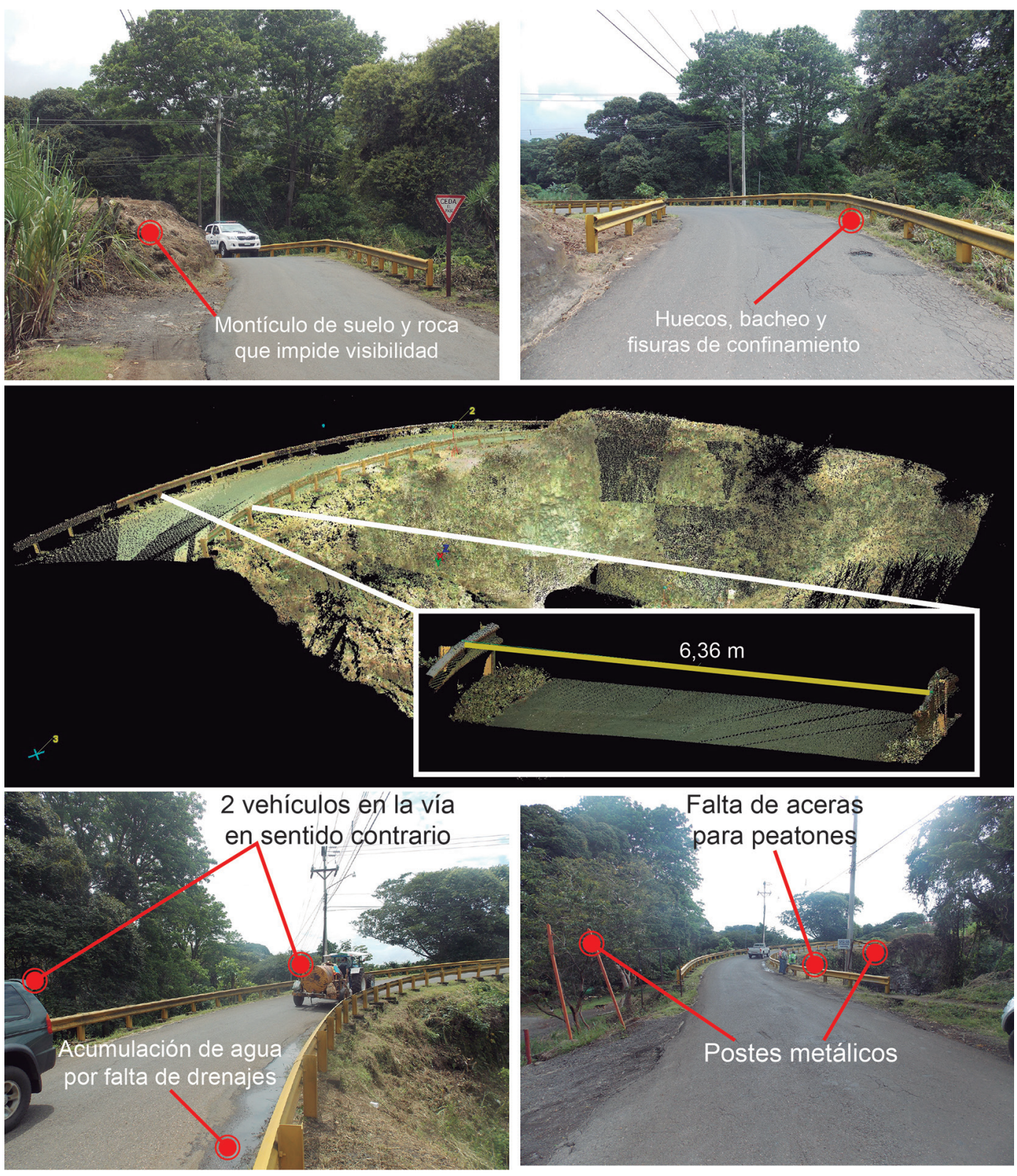

Fig. 11: Se muestran diferentes elementos que afectan la seguridad vial sobre el puente y problemas en la superficie de ruedo. Las fotografías superiores corresponden con el acceso del lado de La Argentina, mientras que las fotografías inferiores corresponden con el acceso del lado de Poró.

del parque nacional y que hoy no están preparados para recibir turistas de forma adecuada.

Con respecto a la oferta turística, es indispensable entender que un visitante puede disfrutar más allá de la zona de los cráteres y que hay otros sitios en los flancos del volcán con atractivos geológicos igual de espectaculares. Además que existen zonas ideales para realizar actividades que se pueden ligar a turismo de aventura y senderismo. Finalmente, en los pueblos de la zona se puede 
disfrutar de otras actividades más tradicionales. Actualmente esta oferta turística funciona de forma desligada y no hay interconexiones en cuanto a los aspectos geológicos, biológicos y culturales. Incluir una visión donde estos campos estén ligados ayudaría a fomentar el desarrollo de las comunidades cercanas al volcán y nos acercaría más a un concepto de geoparque.

De acuerdo con la UNESCO (2016), los geoparques son áreas geográficas individuales, unificados en lugares y paisajes de importancia geológica que son administradas con un concepto integral de la protección, la educación y el desarrollo sostenible. Su enfoque trata de combinar la conservación con el desarrollo sostenible y dando conocimiento a las comunidades. En la actualidad, hay 127 geoparques de la UNESCO en 35 países.

Un geoparque relaciona los aspectos del patrimonio natural y cultural de la zona, para crear conciencia de la importancia del patrimonio geológico de la zona en la historia y en la sociedad de hoy, da a la población local un sentido de orgullo en su región y reforzar su identificación con el área. La creación de empresas locales innovadoras, nuevos puestos de trabajo y cursos de formación de alta calidad se estimula como nuevas fuentes de ingresos se generan a través de geoturismo, mientras que los recursos geológicos de la zona están protegidos (UNESCO, 2016).

Un geoparque - Volcán Poás podría incluir entonces todos los territorios con influencia del macizo, con sitios de belleza, relevancia e impacto geológico, así como de importancia bilógica y cultural. Los rasgos geológicos además serían representativos de la historia geológica del área en particular y de los eventos y procesos que la han formado. Así como de sitios que han sido afectados por eventos destructivos como terremotos o procesos volcánicos. Todo esto fomentaría un sentido de pertenecía a los pobladores y el entendimiento de convivir con un volcán activo.

Actualmente en la zona existen atracciones turísticas que pueden ser alternativas al área de cráteres que permanecerá cerrada en caso de actividad inminente. Estas atracciones poseen las condiciones para ser parte de un geoparque, pero tienen limitaciones en cuanto a su información, infraestructura y acceso. Esto en parte es una de las razones que genera que funcionen de forma aislada del sistema y tengan un desarrollo limitado o mínimo, desperdiciando así un gran potencial para aumentar la oferta turística de la zona. Algunos ejemplos de sitios con estas características son: Laguna Hule, Laguna de Río Cuarto, Laguna de Fraijanes, Cataratas y nacientes los Chorros, Catarata de Río Toro, las aguas termales de Recreoverde y por supuesto Puente de Piedra.

Existen sitios con cataratas fuera del área de los cráteres donde se han desarrollado proyectos exitosos. Son sitios privados con gran atractivo turístico que cuenta buenos servicios e infraestructura. Estos proyectos además de la inversión de sus dueños deben su éxito a que tienen cierta conectividad con el sistema, favorecido por el impulso de las agencias turísticas locales y extranjeras. Han logrado posicionarse gracias a que son una opción con oferta geológica, biológica y cultural alternativa en el bosque nuboso del Poás. Un lugar como este podría fácilmente incluirse dentro del concepto de geoparque.

Consideramos que los sitios con poco desarrollo que han sido mencionados anteriormente y que podrían favorecer la oferta turística en la zona del volcán Poás tienen gran potencial y requieren de visión para poder desarrollar en ellos proyectos de diferentes escalas y que sean exitosos. Aquí nos vamos a enfocar en el caso de Puente de Piedra, pensando en conceptos que también se podrían aplicar en los otros sitios con potencial.

En el Puente de Piedra se podría desarrollar un proyecto de pequeña escala ya sea con inversión privada, del gobierno local o una combinación de ambas. Dentro de las obras que son indispensables en este sitio incluimos: la construcción de un pequeño centro de visitantes donde se pueda comprar suvenires, disfrutar de un café y hasta algo de comer. Este centro de visitantes, debería de contar con servicios básicos, baños y un estacionamiento. Además contar con una zona donde se muestre la información geológica que explique cómo se formó el puente y la comparación con la leyenda tradicional de la zona que explica su origen. Esta leyenda tiene que ser explotada de diferentes formas y con productos relacionados con ella. Para apreciar el paisaje y la belleza geológica del puente, las obras deberían incluir senderos 
bien demarcados y acceso para bajar y atravesar del arco natural. Para observar el puente desde largo y darle un valor agregado a este sitio, se podría incluir la construcción de un puente peatonal colgante, algo similar a los puentes colgantes que hay en otros sitios turísticos del país como Monteverde o cerca del volcán Arenal. Esta estructura debería de colocarse en el sector de aguas arriba, que es donde existe menos vegetación y se puede apreciar mejor el Puente de Piedra. Un puente peatonal de este tipo acercaría más a la población con la estructura natural y desde donde se podrían tomar fotografías. Finalmente consideramos que la iluminación del puente, de sus paredes, arco y aguas es esencial para disfrutar de este lugar aún cuando no haya luz solar y que también sea atractivo de noche y así el centro de visitantes tenga más horas de servicio.

El sector del Puente de Piedra tiene muchas ventajas que se pueden aprovechar para el desarrollo de un proyecto como el descrito anteriormente. Por ejemplo, tiene fácil acceso, tanto por la ruta nacional No. 1 entrando por la Fábrica Nacional de Licores, así como por las carreteras que comunican a Grecia y Sarchí hacia el oeste de Tacares y San Pedro de Poás. Esta accesibilidad podría favorecer que se incluya el sitio en los paseos de un día organizados por las agencias de viajes, que llevan a los turistas al sector de Sarchí y Poás. Otra ventaja es que se puede apreciar y disfrutar aún cuando las condiciones del tiempo no sean óptimas y la nubosidad o lluvia impidan el disfrute de la cima del volcán Poás.

El éxito de un geoparque está en aprovechar y desarrollar sosteniblemente el volcán Poás más allá del cráter principal y su cima. Como hemos visto hay muchos atractivos en las zonas bajas del volcán que están relacionadas geológicamente con el macizo y que tienen gran potencial de desarrollo. Cerca de estos sitios hay potreros, campos de cultivos de fresas, café y caña, bosques y paisajes que también se pueden disfrutar. Además de pueblos pintorescos con costumbres, comidas típicas y actividades que pueden ser parte del mismo sistema. La función del geoparque iría más allá de unificar estos elementos y fomentaría la educación en las ciencias de la tierra y su relación con la sociedad, además de la función de recordar que todas las actividades se están desarrollando sobre un macizo activo donde ocurren procesos como terremotos y erupciones volcánicas que también pueden generar impactos negativos. El proyecto del Puente de Piedra por su tamaño es un sitio ideal para impulsar este tipo de desarrollo para que luego pueda ser replicado en otros lugares.

\section{CONCLUSIONES}

Pese al levantamiento geológico realizado en el Puente de Piedra y alrededores, las relaciones estratigráficas de la Formación Tiribí o Miembro Puente de Mulas en el sitio de estudio, aún no son claras. Por lo tanto, debido a su importancia geológica y turística, se debe incluir este sitio dentro de los puntos que deben ser datados con métodos radiométricos.

Geomorfológicamente la zona donde se ubica el Puente de Piedra es un área de ondulada con pendientes moderada a suave con baja densidad de drenaje. Geológicamente está compuesta por material volcánico como coladas de lava, depósitos de flujos ignimbríticos y material de caída, que por las condiciones climáticas y procesos de meteorización estos materiales producen un suelo de origen volcánico rico en nutrientes que estimuló la expansión agrícola en la zona desde inicios del siglo pasado.

Sin embargo, en los últimos años, el uso de la tierra ha estado cambiando, de campos agrícolas de caña y café a desarrollos urbanísticos. Si esta tendencia continúa con pocos controles y regulaciones, más zonas ocupadas por proyectos habitacionales podrían significar un aumento en el flujo vehicular sobre la estructura natural y tener efectos negativos, como el aumento de vibraciones. La impermeabilización de los suelos por las construcciones provocaría mayor escorrentía y mayor caudal en el río Poró, generando un aumento de la erosión hídrica en el puente.

La erosión causada por las aguas del río Poró y un drenaje natural ubicado al pie del talud izquierdo del puente, ha provocado la socavación de la unidad de tobas inferiores con la abertura de un orificio que atraviesa de lado a lado este costado, que podría generar inestabilidad en la Unidad 
de Tobas soldadas y un eventual colapso produciría un ensanchamiento del arco del puente. Este orificio no fue descrito en el trabajo de Mora et al. (2003), por lo que se considera que su formación es de la última década. Esta nueva condición podría propiciar el colapso de segmentos del techo en la unidad de las tobas soldadas. Además, la vegetación tiene un impacto negativo directo en el puente, en el que las raíces de los árboles y plantas aprovechan los espacios entre las columnas de las para crecer y causan el ensanchamiento de las fracturas, originando desprendimientos de la roca.

En el sector oeste del puente, la existencia de un montículo de suelo y roca alterada representa un serio problema de seguridad vial para los usuarios del puente, disminuyendo la capacidad visual de los conductores. En la actualidad el TPD sobre el Puente de Piedra no significa un problema sobre la estructura, sin embargo, consideramos importante tomar en cuenta que un aumento de este parámetro en el futuro, sí podría tener consecuencias directas sobre la preservación del puente.

Existe la posibilidad de ocurrencia de terremotos en la zona, estos podrían generan aceleraciones considerables y disparar deslizamientos que caigan en los cauces de los ríos generando de flujos de detritos que bajen por el río Poró. Este, es un tipo amenaza para el deterioro o colapso del Puente de Piedra que debe ser estudiado en detalle.

Actualmente, en general el puente se encuentra en buen estado, pero está expuesto a las diferentes actividades que se desarrollan en su entorno, que se consideran como efectos negativos ya sean de bajo o alto impacto.

Finalmente, para la oferta turística y la creación de un geoparque, es indispensable entender que un visitante puede disfrutar más allá de la zona de los cráteres del volcán Poás y que hay otros sitios en los flancos del macizo con atractivos geológicos igual de espectaculares. Además que existen zonas ideales para realizar actividades recreativas ecológicas turísticas.

\section{RECOMENDACIONES}

Realizar un control sobre los cambios de uso de la tierra los alrededores del puente, para mitigar sus efectos en la estructura. Se recomienda hacer otro conteo electrónico de TPD en otro momento del año, cercano a la temporada de recolección de caña y café para determinar si hay un cambio en la cantidad de vehículos pesados. También realizar conteos anuales para hacer correlaciones con el cambio de uso de suelo y aumento de complejos habitacionales en la zona.

Controlar el crecimiento de la vegetación en todos los sectores del puente, taludes aguas arriba y aguas abajo y al lado de la superficie de ruedo. Limpiar con agua o aire a presión y sellar con un impermeabilizante todos los espacios entre las columnas para evitar el crecimiento de vegetación.

Eliminar la vegetación que hay sobre el montículo de suelo y rocas alteradas que hay en el sector oeste del puente. Con esto mejoraría la visibilidad de los conductores y peatones en ambos sentidos de la ruta. Posteriormente se recomienda impermeabilizar el terreno con un sello de concreto para evitar el crecimiento de vegetación y la infiltración de agua en las capas inferiores. Los trabajos de limpieza de este montículo deben que ser controlados y realizados manualmente, debido a que el uso de maquinaría podría dañar la estructura del puente.

Analizar la posibilidad de instalar un semáforo a ambos lados del puente, o bien colocar un espejo cóncavo en la curva para observar el acercamiento de vehículos en cada sentido de la vía.

Revestir con concreto lanzado y malla electro-soldada el material que funciona como la base del puente (unidad de tobas inferior) para evitar que se erosione por acción del agua. Al recubrimiento se le podría dar una textura natural para que el puente no pierda su aspecto natural.

Para los problemas identificados en la superficie de ruedo del puente y las aproximaciones, es recomendable sustituir la capa de mezcla asfáltica y conformar las capas inferiores en los casos que se requiera para dar soporte a la estructura de pavimento, así mismo mejorar la iluminación del puente. Se recomienda construir cunetas y drenajes sobre el puente que realicen un manejo adecuado de aguas superficiales y las lleven a sitios donde el agua no afecte la estructura del puente y los taludes.

Se recomienda realizar estudios donde se modele los flujos de detritos disparados por sismos que bajen por la cuenca del río Poró y lleguen 
hasta Puente de Piedra y así determinar volúmenes mínimos que podrían superar y dañar la estructura. Para determinar la zona de disparo de los deslizamientos que generen los flujos de detritos, se recomienda utilizar modelos heurísticos de susceptibilidad al deslizamiento.

Finalmente, explotar el potencial turístico que esta estructura natural tiene, de esta forma se podrían conseguir fondos para su mantenimiento y preservación. Este uno de los pocos puentes naturales en el mundo que está en funcionamiento. Las acciones recomendadas anteriormente podrían alargar su vida útil y el disfrute de más generaciones.

\section{AGRADECIMIENTOS}

Se agradece a la Municipalidad de Grecia por la colaboración brindada para realizar la inspección de campo y el levantamiento con el escáner lídar. A los ingenieros Roy Barrantes, Ronald Naranjo, José Francisco Garro, Christian Valverde, Josué Quesada, Luis Guillermo Vargas y Jorge Muñoz (Lanamme-UCR), por su colaboración en la realización del informe interno que dio paso a este artículo, a Daniel Solano por la colaboración con las figuras de la formación del puente y a Gerardo Soto por toda su colaboración en el campo y con aportes para la investigación.

\section{REFERENCIAS BIBLIOGRÁFICAS}

Alvarado, G. E.(16 de agosto de 2015). Estructuras de la naturaleza en Costa Rica. Recuperado de http:/www.nacion.com/ocio/artes/ Estructuras-naturaleza_0_1506249367. html

Alvarado, G. E., Morales, L. D., Climent, A. y Rojas, W. (1988). Aspectos sismológicos y morfotectónicos en el extremo occidental de la Cordillera Volcánica Central de Costa Rica. Revista Geológica de América Central, 9, 75-98.

Alvarado, G. E. y Gans, P., (2012). Síntesis geocronológica del magmatismo, metamorfismo y metalogenia de Costa Rica, América Central. Revista Geológica de América Central, 46, 7-122.

American Association of State Highway and Transportation Official AASHTO LRFD BRIDGE, (2012). Design specifications. Washington, DC: American Association of State Highway and Transportation Official.

Cámara Nacional de Ecoturismo y Turismo Sostenible de Costa Rica - CANAECO. (2004). Informe final de foro internacional de ecoturismo Centroamérica. Recuperado de http://www.inbio.ac.cr/web herbarios/ web/foro_regional_eco.htm

Bardales, H. (2013). Conservación de Puente de Piedra en el Perú: criterios para su intervención Estructural (Tesis de maestría inédita). Pontificia Universidad Católica del Perú. Lima, Perú.

Denyer, P., Montero, W. y Alvarado, G. E. (2003). Atlas tectónico de Costa Rica. San José: Editorial Universidad de Costa Rica.

Dirección de Geología y Minas (DGM). (2014). Padrón minero de la Hoja Naranjo (escala 1:50000). San José: DGM.

Gazel, E. y Ruiz, P. (2005). Los conos piroclásticos de Sabana Redonda: Componente magmáticos enriquecidos del volcán Poás. Costa Rica. Revista Geológica de América Central, 33, 45-60.

Gutiérrez, M. E. (2008). Geomorfología. España: Prentice Hall.

Huapaya, S. y Rojas, V. (2012). Mapa geológico de la Hoja Naranjo (3346-III) (escala 1:50 000). San José: DGMP .

Instituto Geográfico Nacional (IGN). (2007). Mapa de Puente de Piedra (escala 1:10 000). San José: IGN. 
Montero, W., Soto, G. J., Alvarado, G. E. y Rojas, W. (2010). División de deslizamiento tectónico y transtensión en el macizo del volcán Poás (Costa Rica), basado en estudios neotectónicos y de sismicidad histórica. Revista Geológica de América Central, 43, 13-36.

Montes, N. (2007). Clasificación de los suelos a partir de sus propiedades físicas, mecánicas e hidráulicas y su relación con el potencial de infiltración en el sector occidental del cantón de Grecia, Alajuela (Tesis de licenciatura inédita). Universidad de Costa Rica, San José, Costa Rica.

Ministerio de Obras Públicas y Transportes (MOPT). (2007). Manual de inspección de puentes. San José: Dirección de Puentes, MOPT.

Mora, R., Chávez, J., Alvarado, M., Camacho, D., Murillo, D., Barrantes, M. y Herrera, P. (2003). Caracterización geológica y geotécnica del Puente de Piedra, Grecia, Alajuela: de la leyenda a la realidad geológica. - 15 págs. G-4213 Mecánica de Rocas, Escuela Centroamericana de Geología, Univ. De Costa Rica.

Mora, R. (2004). El puente de piedra de Grecia: ¿Un arco o un puente natural? Revista Geológica de América Central, (31), 61-66.

Pérez, W. (2000). Vulcanología y petroquímica del evento ignimbrítico del Pleistoceno Medio (0,33 M.a.) del Valle Central de Costa Rica.- 170 págs. Univ. de Costa Rica, San José [Tesis Lic.].
Pérez, W., Alvarado, G.E., Gans P., (2006). The 322 ka Tiribí Tuff: stratigraphy, geochronology and mechanisms of deposition of the largest and most recent ignimbrite in the Central Valley, Costa Rica. - Bul. Volcanol. 69: 25-40.

Porres, J. A. (2007) Puente natural de Puentedey. Burgos, España: Asociación geocientífica de Burgos.

Programa de las Naciones Unidas para el Desarrollo (PNUD), Instituto Meteorológico Nacional (IMN) y Ministerio de Ambiente y Telecomunicaciones (MINAET). (2009). Diagnostico biofísico para Costa Rica. San José: ECOTEC.

Programa de Planificación Urbana de la Gran Área Metropolitana (PRUGAM). (2010). Mapa uso de la tierra (escala 1:10 000). San José: PRUGAM.

Quiros, L., Miranda, P. y Alfaro, C. (2014). El turismo en volcanes de Costa Rica: caso volcán Poás. Recuperado de http://observatoriogeograficoamericalatina.org. $\mathrm{mx} /$ egal13/Geografiasocioeconomica/ Geografiaturistica/18.pdf

Ramos, V., Kay, S. M. y Pérez, D. J. (1996). Geología de la región del Aconcagua, provincias de San Juan y Mendoza. Anales de la Subsecretaría de Minería de la Nación, Dirección Nacional del Servicio Geológico, 24(10), 300.

Rodríguez, G. O. (2005). Puente del Inca. Monumento Natural Provincial - 
Mendoza. Recuperado de http://www.patrimonionatural.com/HTML/provincias/ mendoza/puenteinca/descripcion.asp

Ruiz, P., Gazel, E., Alvarado, G. E., Carr, M. J. y Soto, G. J. (2010). Caracterización geoquímica y petrográfica de las unidades geológicas del macizo del volcán Poás, Costa Rica. Revista Geológica de América Central, 43, 37-66.

Ruiz, P., Garro, J. F. y Soto, G. J. (2014). El uso de imágenes lídar en Costa Rica: Casos de estudio aplicados en geología, ingeniería y arqueología. Revista Geológica de América Central, 51, 7-31.

SINAC. (s.f.). Parque Nacional Volcán Poás. Recuperado de http://www.sinac.go.cr/ES/ ac/accve/pnvp/Paginas/default.aspx

Sistema Nacional de Áreas de Conservación (SINAC). (2016). Información volcán Poás.
Recuperado de http://www.sinac.go.cr/ES/ ac/accve/pnvp/Paginas/default.aspx

Unidad de Gestión y Evaluación de la Red Vial Nacional (UGERVN). (2014). Informe de evaluación del estado del Puente de Piedra, Grecia: Laboratorio Nacional de Materiales y Modelos Estructurales. Informe interno.

UNESCO. (2016). What is a UNESCO Global Geopark?. Recuperado de http://www. unesco.org/new/en/natural-sciences/environment/earth-sciences/unesco-globalgeoparks/frequently-asked-questions/ what-is-a-unesco-global-geopark

Wilbur, J. H. (2003). Natural arch in formation. Recuperado http://www.naturalarches.org/ archinfo/

Zeledón, C. E. (2000). Leyendas costarricenses ( $4^{\text {ta }}$ ed.). Heredia: Editorial de la Universidad de Nacional de Costa Rica. 
